\title{
درجة التوافر والأهمية لمتطلبات تطبيق إدارة المعرفة في الإشراف التربوي من وجهة نظر المشرفين بسلطنة عُمان
}

\section{بدرية بنت علي الفارسية}

مشرفة تربوية بالمديرية العامة للتربية

والتعليم- مسقط- سلطنة عُمان

b.farsi@moe.om
نسرين صالح محمد صلاح الدين

أستاذ الإدارة التربوية المساعد- كلية التربية

جامعة السلطان قابوس- سلطنة عُمان

nesren@squ.edu.om 


\title{
درجة التو افر والأهمية لمتطلبات تطبيق إدارة المعرفة في الإشراف التربوي من وجهاة نظر المشرفين بسلطنة عُمان
}

\author{
نسرين صالح محمد صلاح الدين \\ أستاذ الإدارة التربوية المساعد- كلية التربية- جامعة السلطان قابوس- سلطنة عُمان \\ nesren@squ.edu.om \\ بدرية بنت علي الفارسية \\ مشرفة تربوية بالمديرية العامة للتربية والتعليم- مسقط- سلطنة عُمان \\ b.farsi@moe.om
}

DOI: https://doi.org/10.31559/EPS2021.9.3.9 2020/11/5: 2020/10/14 مراجعة استلام البحث البحث: 2020/10/20

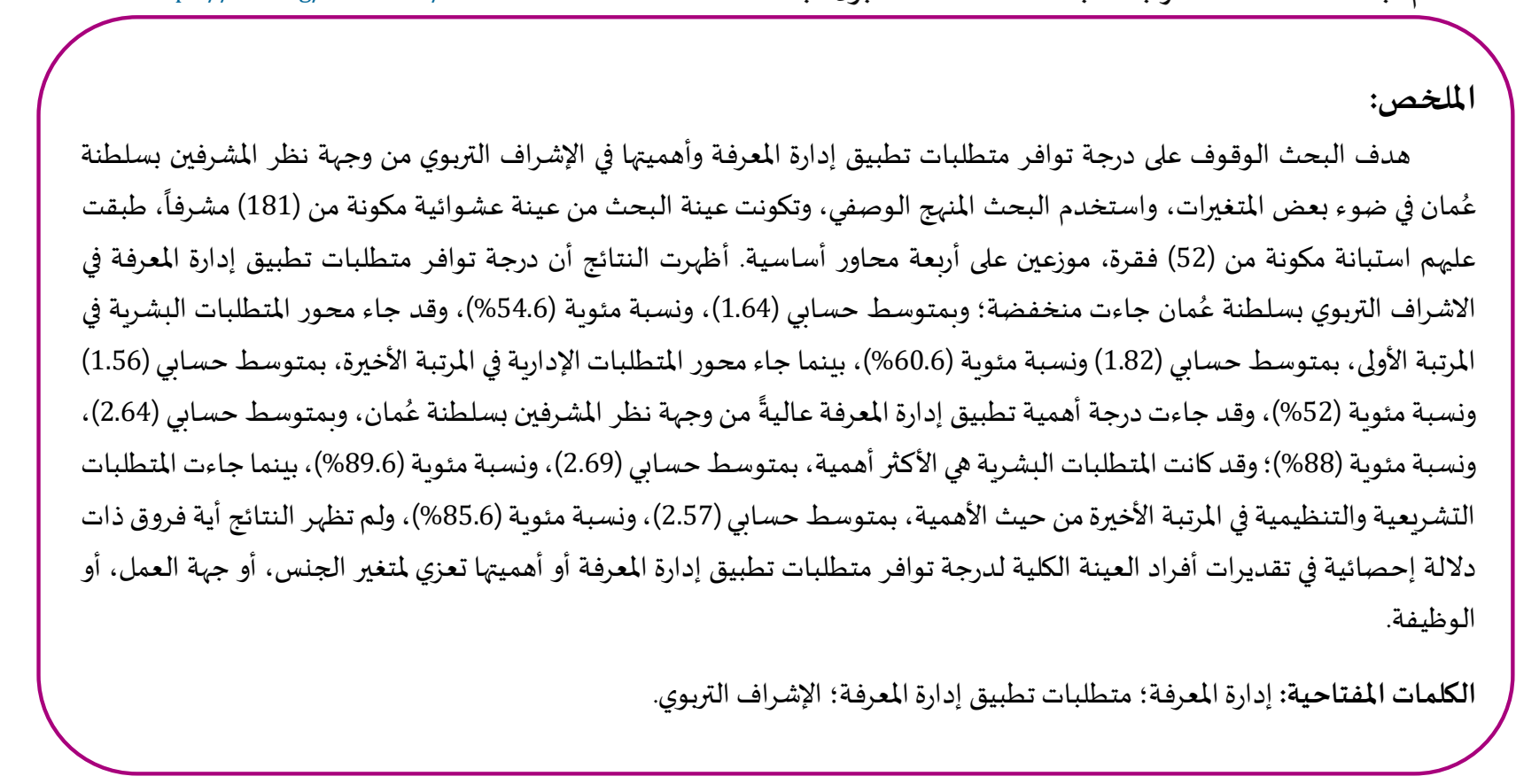

المقدمة:

شهدت البشرية على مر العصور العديد من الثورات منها: الاجتماعية، والصناعياة، والعلمية، والتكنولوجياة، ساهمت جميعها في تحديد ملامح العصر الحديث، الذي يعتمد بشكل أساسي على التقنية الهائلة والانفجار المعرفي.

تعتبر المعرفة عصب منظمات اليوم، ووسيلة إدارية حديثة للتكيف مع متطلبات العصبر، ومع تزايد دور المعرفة في إنجاح المنظمات

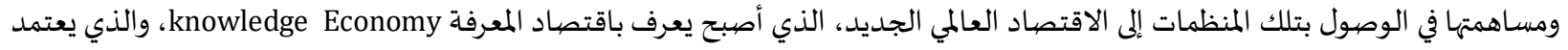
على رأس المال الفكري، وعلى التنافس من خلال القدرات البشرية أكثر من العناصر التقليدية، وضع تحدي أمام المنظمات للبحث عن أفضل 
الطرق لإدارتها، فقد حدث تحول في العلاقة بين المعرفة والإدارة، أي التحول إلى مرحلة إدارة المعرفة، فالإدارة تحولت من مجرد مجال يستفيد من المعرفة إلى مستوى أعلى يتحكم بها، أي أن الإدارة قد قفزت فوق المعرفة، فأصببحت تحكم في مسارها وفي ضبط جغرافيتها (حامد، 2006). وقد أشـار شوي ويونغ (Choy \& Yong, 2005) إلى أن إدارة المعرفة تبرز كتحدي تنظيمي وإداري للمنظمات، لاسيما مع الدور البارز الذي تلعباء تكنولوجيا المعلومات والاتصالات كمحفز لتطوير المعرفة، وتمكين المنظمات من المنافسة بشكل أفضل من أجل البقاء والتميز. ومن ثم أصبحت إدارة

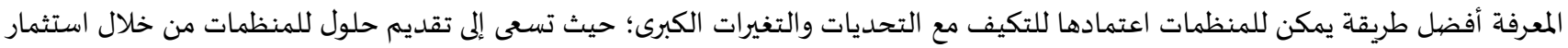

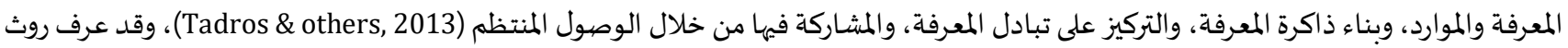
ولي (Roth \& Lee, 2009) إدارة المعرفة بأنها عملية مستمرة تتضمن أنشطة متنوعة تتمثل في تشخيص وتصريميم وتنفيذ بناء المعرفة، ونقلها وتبادلهاء

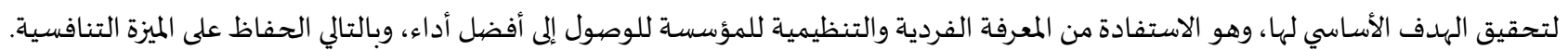

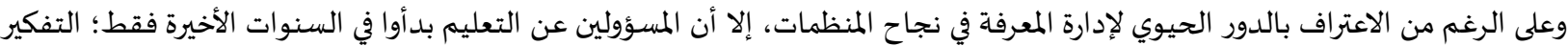

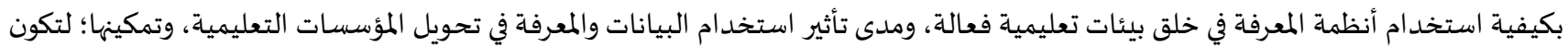

قادرة على تجديد نفسها باستمرار (Kaya, 2019).

وبالتالي يجب أن تقف المؤسسات التربوية المتطورة على رأس قائمة المؤسسات الساعية للحصيول الحسول على المعرفة المتجدددة، وتوظيفها، مما يتطلب قادة تربويين ممكنين، قادرين على انجاز الأعمال بطرق مبتكرة وتفكير خلاق، الأمر الذي سيؤدي إلى إنتاجية متميزة من خلال توظيف هؤلاء القادة والأفراد

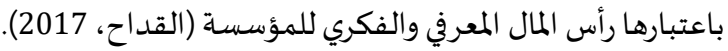
وقد أشـارت العديد من الدراسـات والبحوث إلى أهمية إدارة المعرفة في رفع مستوى العملية التعليمية، وتحقيق أهدافها بأفضل العوائد ألمائد وأقل

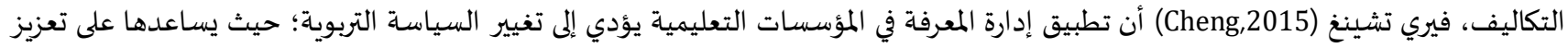

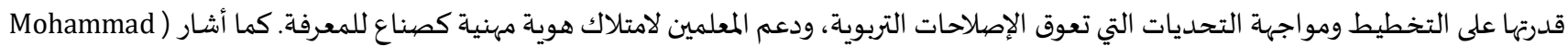
(\& Jose, 2016 إلى أن إدارة المعرفة في القطاع التعليمي أصبحت ضهرورة ملحة؛؛ لأها تتيح الفرصة للتركيز على تبني الخيارات الصحيحة والمناسبة، وزيادة

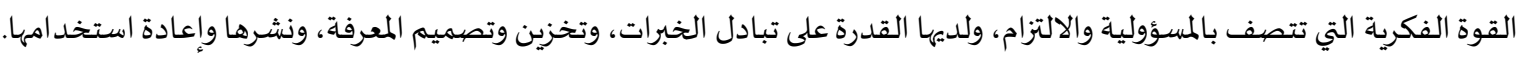

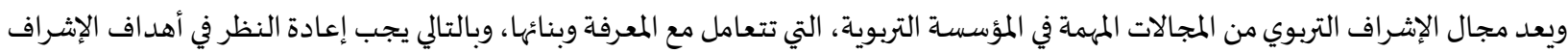

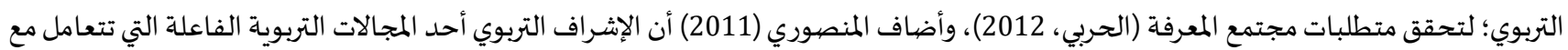
نشر وتطبيق المعرفة والافادة منها؛ نتيجة لكون المشرف التربوي أحد أركان خط الدفاع المربه الأول الذي يتصدى لمواجهة المشكلات الواقعية، ولإيجاد حلول

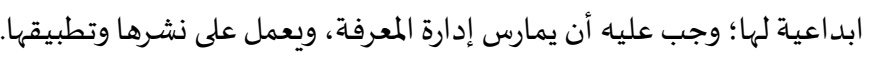

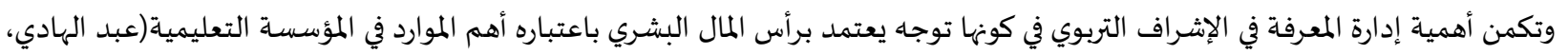

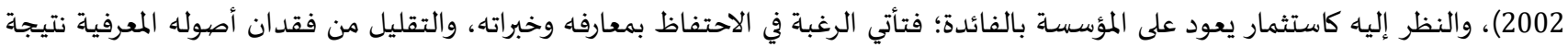

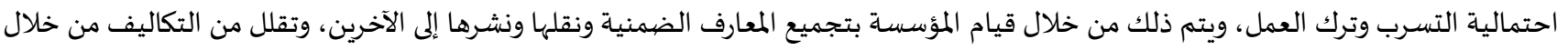

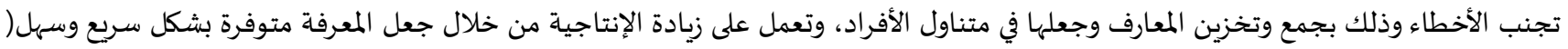
الكبيسي، 2005).

ويظهر دور المشرف التربوي كأحد صناع المعرفة الذين يقومون ببناء المعرفة كجزء من عملهم، ويقوم بتوفير الموجودات أو الموارد غير المادية التي تصبح حيوية للنجاح والنمو التنافسي، وبربط وتنظيم المعلومات مع بعضها البعض، وعبر التقييم المستمر للمعلومات المحفوظة في الأنظمة التقنية (الخطيب ومعايعة، 2009؛ العلي وآخرون، 2006؛ القطارنة، 2011). كما يقوم المشرف التربوي بدور مدير إدارة المعرفة؛ حيث يقوم ببناء علاقات عمل جيدة مع الإدارة العليا ومع العاملين في الأقسام الأخرى، وهذا

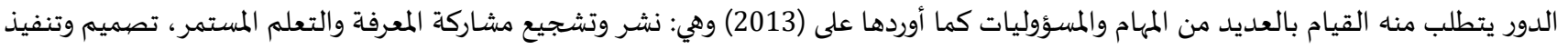

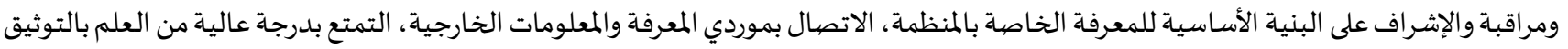
والمكتبات، ولديا خبرة بمجالات إعادة هندسة المعلومات الحديثة، إدارة التغيير، وتطوير المنظمات.

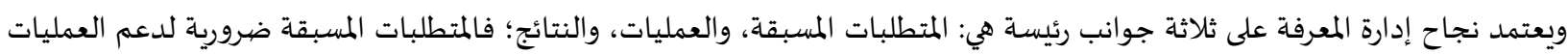

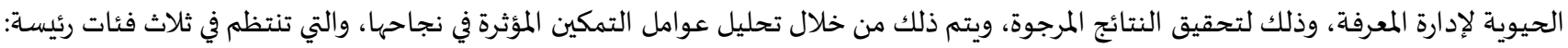

الفردية والتنظيمية والتكنولوجية (Nunes \& others, 2017).

ومن ثم يتطلب تطبيق إدارة المعرفة بالمؤسسات التعليمية بشكل عام، وفي الإشراف التربوي بشكل خاص مجموعة من المتطلبات من أهمها ما يلي: (

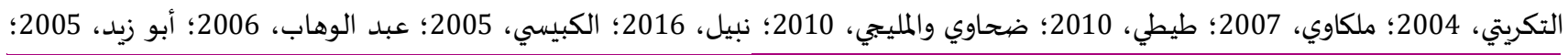
859 
صياغة رؤية للمؤسسة يشترك فهيا جميع العاملين، وتوضح كيفية إدارة الأصول المعرفية، وإنشاء نظام معلوماتي داخل المؤسسـة، مما يسهل تبادل المعرفة والحصهول على مصادرها ويتيح الفرصة لنقلها وتقاسمها، وتكوين فريق إدارة المعرفة بالمؤسسة، وتطوير وتنمية قدرات

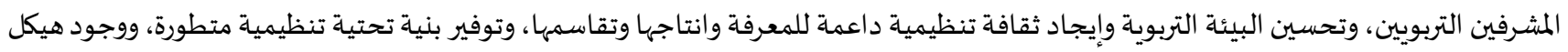
تنظيمي مرن، والإدارة الاستراتيجية للأصول المعرفية بالمؤسسات، والابتكار والتأكيد على فرص التعلم المستمر للأفراد، توفير الفرص للأفراد للمشاركة

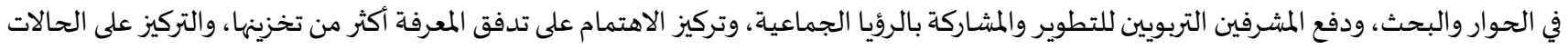

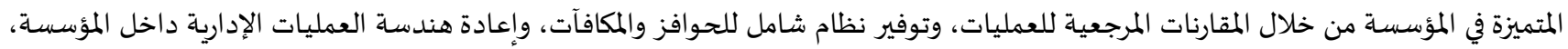

واستثمار المعرفة التنظيمية، والتوجه نحو نمط المؤسسة التعليمية المتعلمة، والتوسع في استخدام التمات التكنولوجيا الحديثة.

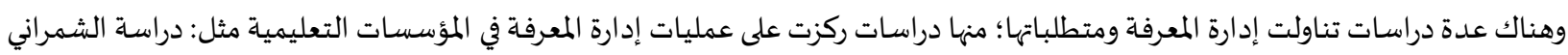

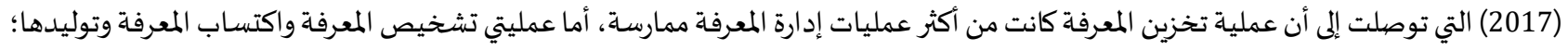

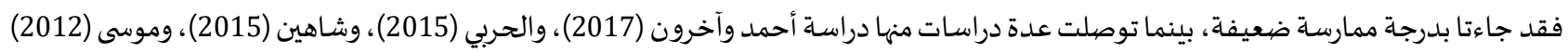
إلى أن تطبيق إدارة المعرفة جاء بدرجة متوسطة، بينما أظهرت دراسة الحبسية (2012) أن دور إدارة المعرفة في تنمية المهارات الإدارية لدى العادية العاملين

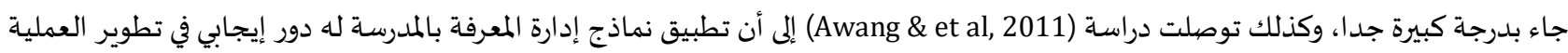

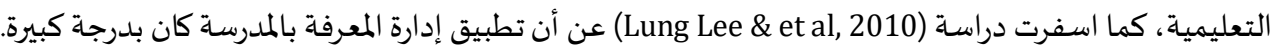

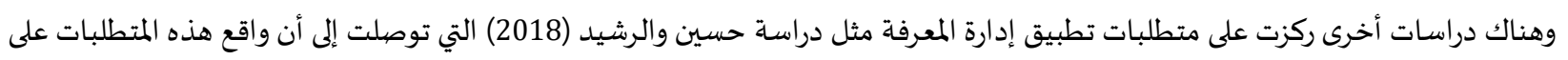
المستوى الكلي جاء بدرجة مرتفعة، في حين توصلت دراسة الطويسي (2017) إلى ضرورة تطوير أدوار ومهام الإشراف والتشريعات المنظمة لله؛ وأظهرت

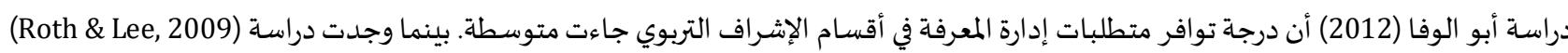

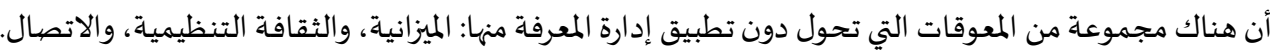
وفي سلطنة عمان، يعد الإشراف التربوي أحد أهم جوانب العملية التربوية، وحظي باهتمام كبير في ظل رؤية تطوير النظام التعليمي، انطلاقا من

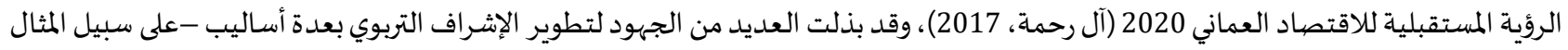

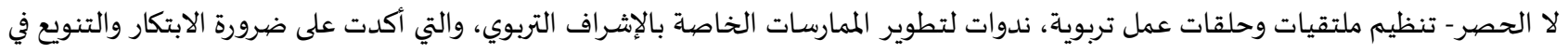

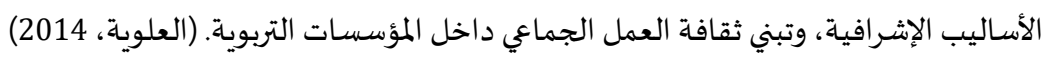

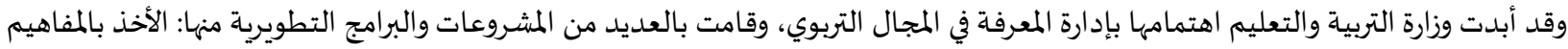

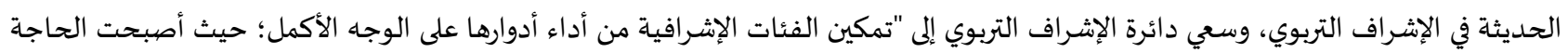
ملحة إلى تفعيل الأداء النوعي للمشرف التربوي". (وزارة التربية والتعليم، 2017)

مشكلة الدراسـة:

على الرغم من الجهود المبذولة من قبل وزارة التربية والتعليم بالسلطنة لتطبيق إدارة المعرفة في الإشراف التربوي، إلا أنه ما زال هناك قصور في

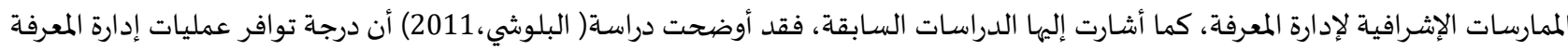
في دوائر تنمية الموارد البشرية ومكاتب الإشراف التربوي جاءت بدرجة متوسطة، وأن هناك صعوبات تواجه تطبيق إدارة إدارة المعرفة في دوائر تنمية الموارد البشرية جاءت بين المتوسطة والعالية، كما أشارت دراسة (الجهوري، 2016) إلى أن عمليات تدريب وتخطيط وتقويم الأداء لتنمية الموارد البشرية في ضوء مدخل إدارة المعرفة جاءت بين المتوسطة والضعيفة، كما وصلت دراسة الحبسية (2012) إلى وجود قصيور لدى العاملين بالمديريات التعليمية في الدور الذي تلعباء إدارة المعرفة في تنمية المهارات الإدارية لديهم.

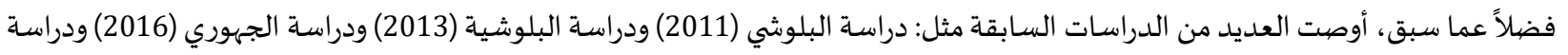
الحبسية (2017) ودراسة القاسمية (2009) ودراسة المنصوري (2011) بتبني ثقافة تنظيمية داعمة لإدارة المعرفة، والعمل على توفير متطلبات تطبيق إدارة المعرفة في قطاع التعليم، والأخذ بمبادئ الاقتصاد المعرفي في تطوير النظام التربوي، وإجراء المزيد من الدراسات حول عمليات إدارة المعرفة تلفية ومتطلبات تطبيقها. وفي ضوء ما سبق يتضح أن هناك حاجة لإجراء هذا البحث الذي يتناول متطلبات تطبيق إدارة المعرفة في الإشراف التربوي بسلطنة عمان. 
أسئلة الدراسـة:

تحاول الدراسـة الإجابة عن في الأسئلة التالية:

1. ما درجة توافر متطلبات تطبيق إدارة المعرفة في الإشراف التربوي بسلطنة عمان من وجهة نظر المشرفين؟

2. ما درجة أهمية متطلبات تطبيق إدارة المعرفة في الإشراف التربوي بسلطنة عمان من وجهة نظر المشرفين؟

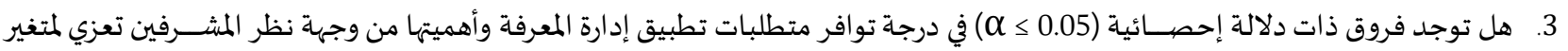
الجنس أو الوظيفة أو جهة العمل؟ بؤد

أهداف الدراسـة:

تسعى الدراسة التالي إلى تحقيق ما يلي:

1. تحديد درجة توافر متطلبات تطبيق إدارة المعرفة في الإشراف التربوي بسلطنة عمان.

2. تحديد درجة أهمية متطلبات تطبيق إدارة المعرفة في الإشراف التربوي بسلطنة عمان.

3. الكشف عن أي فروق دالة إحصائياً في تقديرات المشرفين المتعلقة بمتطلبات تطبيق إدارة المعرفة ودرجة أهميتها وفقا لمتغير الجنس أو الوظيفة

أو جهة العمل.

أهمية الدراسـة:

تنبع أهمية هذه الدراسة من خلال:

1. قلة الدراسات العمانية التي تناولت متطلبات تطبيق إدارة المعرفة في الإشراف التربوي بسلطنة عمان من حيث توافرها وأهميتها. 2. قد تفيد نتائج البحث واجراءاته المقترحة المسؤولين في وزارة التربية والتعليم في اتخاذ إجراءات التي تسهم في زيادة تطبيق إدارة المعرفة في الإشراف التربوي والمؤسسات التربوية، مما يؤدي إلى جودة العملية التعليمية ككل.

حدود الدراسـة:

اقتصرت الدراسة على الحدود الآتية:

الحددود الموضوعية: اقتصر البحث في تناوله لمتطلبات تطبيق إدارة المعرفة على المتطلبات الأربع الآتية: التشريعية والتنظيمية، والإدارية، والبشرية، والمادية والتكنولوجية.

الحسود البشرية: تناول البحث جميع المشرفين (العموم- الأوائل- التربويين) بديوان عام الوزارة، وبدوائر تنمية الموارد البشرية في المديريات التعليمية بالمحافظات. •الحدود المكانية: تم تطبيق أداة البحث على جميع المحافظات التعليمية بالسلطنة وعددهم (11) محافظة. الحسدود الزمانية: من شهر فبراير 2019 إلى شهر مايو 2020م.

مصطلحات الدراسـة:

إدارة المعرفة Knowledge Management: هناك عدة تعريفات لإدارة المعرفة منها ما يلي:

مجموعة من العمليات التي تتضمن تحديد وتخطيط الأصول الفكرية، ورأس المال الفكري والمعرفي في المؤسسـة، وابتكار وتوليد معرفة جديدة بهدف

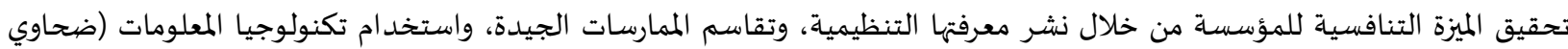

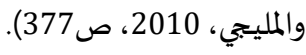

" مجموعة العمليات المساعدة للمنظمة في الحصول على المعرفة بما فيها من (بيانات، ومعلومات، واتجاهات، وخبرات، وقدرات) توجه الأنشطة

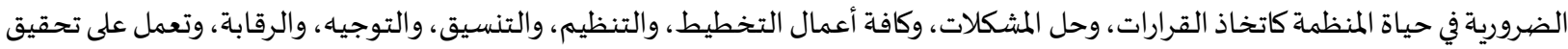

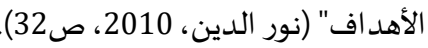

إدارة العمليات التي تحكم خلق ونشر واستخدام المعرفة بدمج التكنولوجيا وهيكل المنظمة والأفراد؛ لإيجاد تعلم فعال، وحل مشكلات، واتخاذ

قرارات بالمنظمة (العلي وآخرون، 2006؛ علي، 2013). 
العمليات التي تسـاعد المنظمات على اكتساب المعرفة وتوليدها واختيارها وتنظيمها واستخدامها ونشرها وتحويل المعلومات والخبرات الضرورية

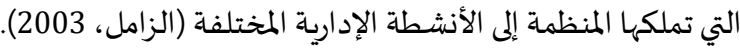
وباستقراء التعريفات السـابقة لإدارة المعرفة يمكن تعريف إدارة المعرفة إجرائيا بأهها مجموعاة من العمليات التي تمكن جميع العاملين في الإشراف

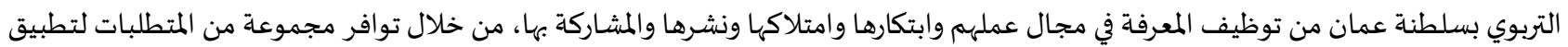

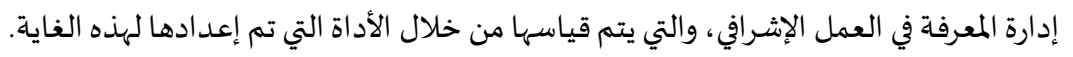

متطلبات إدارة المعرفة:

تعرف المتطلبات بشكل عام بأنها “الاحتياجات اللازمة لإنجاز عمل ما، والقيام باه وفق معايير محددة مسبقاً” (بدوي، 1977، 42)، كما يحددها قاموس أكسفورد (Oxford, 1993,732) بأها شيء يستلزم وجوده أو هو شيء يجب توافره أو هو الشيء الذي تكرر أهمية وجوده وهو شرط لتحقيق نتائج معينة.

ومن ثم تعرف متطلبات إدارة المعرفة إجرائياً بأنها الشروط والاحتياجات التشريعية والتنظيمية، والإدارية، والبشرية، والمادية والتكنولوجية اللازمة لتمكين جميع العاملين في الإشراف التربوي بسلطنة عمان من توظيف المعرفة في مجال عملهم وابتكارها وامتلاكها ونشرها والمشاركة بها.

\section{منهجية الدراسـة وإجراءاتها:} منهـج الدراسـة:

استخدمت الدراسة المنهج الوصفي باعتباره "الطريقة البحثية التي يعتمد عليها الباحثون في الحصول على معلومات وافية ودقيقة تصور الواقع

الاجتماعي، وتسهم في تحليل ظواهره تحليلاً كافيًا ودقيقًا، لاستخلاص دلالاتها، والوصول إلى نتائج أو تعميمات عن الظاهرة (الكسباني، 2012، 86).

مجتمع الدراسة وعينتها:

يمثل مجتمع الدراسة جميع المشرفين العموم والأوائل في ديوان عام وزارة التربية والتعليم، وجميع المشرفين الأوائل والتربويين بدوائر تنمية الموارد البشرية في المديريات التعليمية بمحافظات السلطنة، للعام الدراسي 2020/2019، والبالغ عددهم (11) مشرف عام، و( 44) مشرف أول بالوزارة، وا 77) مشرف أول بالمديريات التعليمية، و (1276) مشرف تربوي (وزارة التربية والتعليم، 2019، 103)، وقد تم تطبيق الاستبانة المانة إلكترونيا عبر البريد

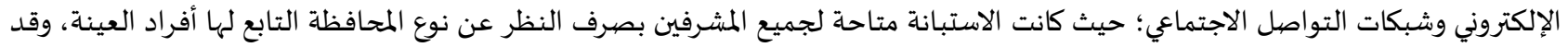
وصل عدد المستجيبين على الاستبانة (181) مشرف بسلطنة عمان، والجدول التالي يوضح خصيات خيائص عينة الدراسة.

جـدول (1): الخصائص الديموغر افية لعينة الدراسة (الجنس، مكان/جهة العمل، الوظيفة)

\begin{tabular}{|c|c|c|c|}
\hline النسبة (\%) & العدد & المستوى & المتغير \\
\hline 54.1 & 98 & ذكر & الجنس \\
\hline 45.9 & 83 & أنثى & \\
\hline$\% 100$ & 181 & المجموع & \\
\hline 2.2 & 4 & مشرف عام & الوظيفة \\
\hline 7.7 & 14 & مشرف أول & \\
\hline 90.1 & 163 & مشرف تربوي & \\
\hline$\% 100$ & 181 & المجموع & \\
\hline 8.3 & 15 & الوزارة & مكان/جهة العمل \\
\hline 91.7 & 166 & المديرية & \\
\hline$\% 100$ & 181 & المجموع & \\
\hline
\end{tabular}

يتضح من الجدول (1) أن نسبة الذكور تقترب من نسبة الإناث المشاركة في الدراسة؛ حيث كانت نسبة الذكور والاناث (54.1\%، 45.9\%) على التوالي، وأن معظم عينة الدراسة من المشرفين التربويين (90.1\%) من المديريات التعليمية بالمحافظات؛ حيث تبلغ نسبتهم (91.7\%). 
اعتمدت الدراسة على الاستبانة كأداة لجمع البيانات، وتم تصميمها من خلال مراجعة، وتحليل الأدبيات المرتبطة بموضوع البحث، وكذلك الكاتك الاستفادة من الأدوات التي استخدمتها الدراسات السابقة مثل دراسـة القاسمية (2009)، الحبوب (2010)، المنصبوري (2011)، الحبسية (2012)، الشاعر (2012)، الحربي (2012)، البلوشية (2013)، الجهوري (2016)، القدوات التداح (2017)، وكروان (2017).

وتضيمنت الاستبانة في صورتها الأولية جزأين؛ الجزء الأول ارتبط بالبيانات الأولية مثل الجنس ومكان العمل والوظيفة، والجزء الثاني يحتوي على

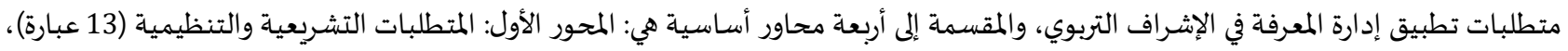

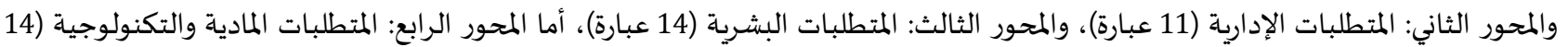
عبارة)، وتم تحديد الإجابات فيها حسب مقياس ليكرت الثلاثي لدرجة التوافر بدرجة (كبيرة- متوسطة-قليلة)، ودرجة الأهمية بدرجة (كبيرة- متوسطة-

للتحقق من مدى صدق الاستبانة في قياس ما وضعت لقياساه تم تحكيمها في صورتها الأولية من قبل مجموعة من المحكمين من ذوي الخبرة والاختصاص في الإدارة التربوية، وفي ضوء مقترحاتهم وملاحظاتهم تم إجراء التعديلات التي اجمعوا عليها، وتعديل صياغة بعض العبارات التهات التي اقترحوا ضرورة إعادة صياغاتها، وفي ضوء آرائهم تم إعداد الاستبانة، ومن ثم تطبيقها على العينة الاستطلاعياة.

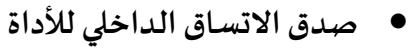

لمعرفة صداق الاتساق الداخلي للاستبانة تم حساب معامل الارتباط بيرسون Pearson correlation بين درجة كل محور من محاور الاستبانة

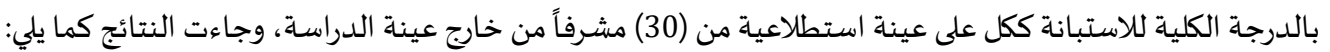
جدول (2): معاملات الارتباط بين درجة كل محور من محاور الاستبانة والاستبانة ككل

\begin{tabular}{|c|c|c|c|c|c|}
\hline الدرجة الكلية & والمتطلبات المادية & المتطلبات & المتطلبات & المتطلبات التشريعية & المحاور \\
\hline **0.934 & $* * 0.657$ & $* 0.784$ & $* * 0.903$ & 1 & المتطلبات التشريعية \\
\hline${ }^{* *} 0.948$ & $* * 0.656$ & $* 0.821$ & 1 & **0.903 & المتطلبات الإدارية \\
\hline$* * 0.881$ & $* * 0.528$ & 1 & $* * 0.821$ & $* * 0.784$ & المتطلبات البشرية \\
\hline${ }^{* *} 0.801$ & 1 & $* * 0.528$ & $* * 0.656$ & **0.657 & والمتطنلبات المادية \\
\hline 1 & $* * 0.801$ & ${ }^{* *} 0.881$ & ${ }^{* *} 0.948$ & ${ }^{* *} 0.934$ & الدرجة الكلية \\
\hline
\end{tabular}

يبين الجدول رقم (2) معاملات ارتباط بيرسون بين محاور الاستبانة وبين الدرجة الكلية؛ حيث يلاحظ وجود علاقة طردية قوية بين جميع محاور الاستبانة، وكذلك بين المحاور والاستبانة ككل؛ فقد تراوحت معاملات الارتباط بين (0.528 - 0.948)، وهي جميعها دالة عند مستوى دلالة (

للتحقق من ثبات أداة الدراسة تم استخدام معامل ثبات ألفا لكرو نباخ (Cronbach's Alpha Coefficient) لحساب اتساق درجات أفراد العينة

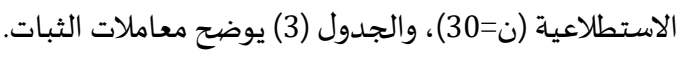

جدول (3): معاملات ثبات ألفا كرو نباخ لمحاور أداة البحث

\begin{tabular}{|c|c|c|}
\hline معامل ألفا كرو نباخ & عدد المفردات & محاور الاستبانة \\
\hline 0.919 & 13 & المتطلبات التشريعية والتنظيمية \\
\hline 0.933 & 11 & المتطلبات الإدارية \\
\hline 0.932 & 14 & المتطلبات البشرية \\
\hline 0.944 & 14 & المتطلبات المادية والتكنولوجية \\
\hline 0.974 & 52 & \\
\hline
\end{tabular}


يتضح من خلال الجدول (3) أن قيمة معامل ألفا لكرو نباخ لمحاور الاستبانة تراوحت بين (0.919- 0.944)، أما الاستبانة ككل فقد بلغ معامل

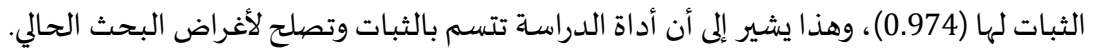

الأسـاليب الإحصيائية:

استخدمت المعالجات الإحصائية والوصفية المناسبة في استخراج النتائج لكل سؤال من أسئلة البحث باستخدام برنامج الرزمة الإحصيائية للعلوم

الاجتماعية (SPSS) كما يلي:

1. تم استخدام معامل الارتباط ألفا كرونباخ (Alpha Cronbach)، ومعاملات ارتباط بيرسون (Pearson)، للتأكد من صدق وثبات أداة الدراسـة. 2. تم حساب المتوسطات الحسابية والانحرافات المعيارية للإجابة عن السؤال الأول والثاني.

3. تم استخدام اختبار (T-Test)، للإجابة عن السؤال الثالث؛ لبيان دلالة الفروق بين متوسطات عينتين مستقلتين؛ للتعرف على وجود فروق تعزى

لمتغير الجنس.

4 4. تم استخدام تحليل التباين الأحادي (ON WAY ANOVA)، لبيان دلالة الفروق بين متوسطات ثلاث عينات فأكثر، ولإجابة عن السؤال الثالث، وللتعرف على مدى وجود فروق ذات دلالة إحصائية تعزى لمتغير الوظيفة، ومكان/ جهة العمل، وتم استخدام اختبار شيفياه للمقارنات البعدية بين المتوسطات

الحسابية وفقًا لمتغير الوظيفة.

واعتمد البحث على مقياس ليكرت الثلاثي لإجابات عينة الدراسـة والذي تكون من (كبيرة، متوسطة، قليلة) ودرجاتها على التوالي (3، 2، 1)، والجدول

رقم (4) يوضح هذا المقياس، وذلك من خلال حساب مدى الفئات بالمعادلة التالية:

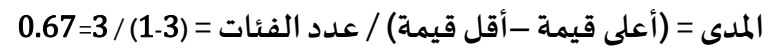

\begin{tabular}{|c|c|}
\hline المتوسط الحسابي (طول الخلية) & درجة التو افر/ الأهمية \\
\hline من 1 إلى أقل من 1.67 & منخفضة \\
\hline من 1.67 إلى أقل من 2.34 & متوسطة \\
\hline من 2.34 إلى 3 & كبيرة \\
\hline
\end{tabular}

نتائج الدراسـة ومناقشتها:

أولاً: النتائج المتعلقة بالسؤال الأول: "ما درجة تو افرمتطلبات إدارة المعرفة في الإشراف التربوي بسلطنة عمان من وجهة نظر المشرفين"؟

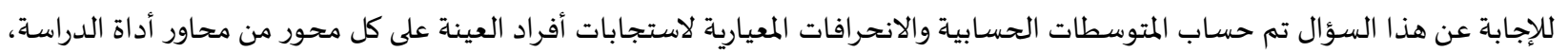
وجدول (5) يوضح ذلك.

جدول (5): المتوسطات الحسابية والانحر افات المعيارية والنسب المئوية لدرجة تو افرمتطلبات إدارة المعرفة في الإشراف التربوي من وجهة نظر

\begin{tabular}{|c|c|c|c|c|c|c|}
\hline \multicolumn{7}{|c|}{ المشرفين } \\
\hline 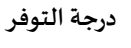 & 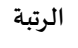 & النسبة & 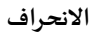 & المتوسط & المحور & م \\
\hline & & 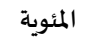 & 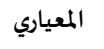 & الحسابي & & \\
\hline منخفض & 2 & $\% 53.6$ & 0.399 & 1.61 & المتطلبات التشريعية والتنظيمية & 1 \\
\hline 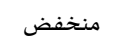 & 4 & $\% 52$ & 0.457 & 1.56 & المتطلبات الإدارية & 2 \\
\hline متوسط & 1 & $\% 60.6$ & 0.441 & 1.82 & المتطلبات البشرية & 3 \\
\hline منخفض ل & 3 & $\% 52$ & 0.439 & 1.57 & المتطلبات المادية والتكنولوجية & 4 \\
\hline منخفض & & $\% 54.6$ & 0.379 & 1.64 & الدرجة الكلية & \\
\hline
\end{tabular}

يتضح من الجدول (5) أن المتوسطات الحسابية لاستجابات أفراد عينة الدراسة تراوحت بين (1.56- 1.82)، وبنسب مئوية تباينت ما بين (52\%

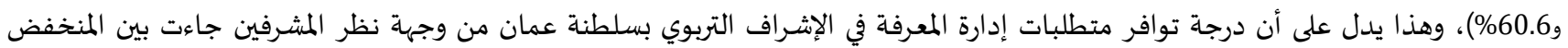
والمتوسط؛ حيث جاء محور المتطلبات البشرية في المرتبة الأولى بمتوسط حسابي (1.82) وبنسبة مئوية (60.6\%) وبدرجة توافر متوسطة، بينما جاء محور المتطلبات الإدارية في المرتبة الأخيرة بمتوسط حساءئ (1.56)، وبنسبة مئوية (52\%) وبدرجة توافر منخفضية. وبلغ المتوسط الحسابي للاستبانة ككل 
(1.64) وبنسبة مئوية (54.6\%) وبدرجة توافر منخفضة،، مما يدل ذلك على أن الدرجة العامة لتوافر متطلبات إدارة المعرفة في الإشراف التربوي بسلطنة عمان من وجهاة نظر المشرفين منخفضية. وقد يرجع ذلك إلى نهج المركزية الذي تتبعاه وزارة التربية والتعليم بالسلطنة، والذي يؤدي للحد من تطبيق الأساليب والمداخل الإدارية الحديثة في

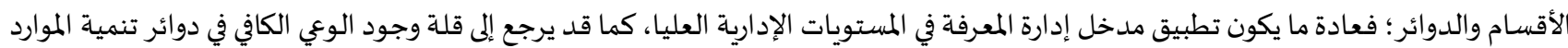

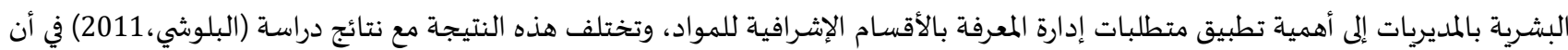

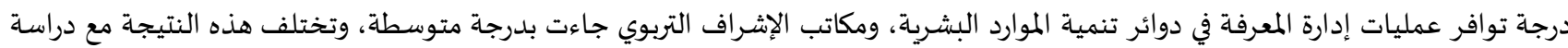

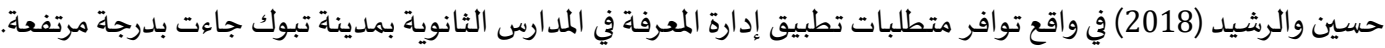
ولمعرفة تقديرات المشرفين لفقرات محاور أداة الدراسة (المتطلبات التشريعية والتنظيمية ، والمتطلبات الإدارية، والمتطلبات البشرية، والمتطلبات المادية والتكنولوجية) تم حساب المتوسطات الحسابية والانحرافات المعيارية والنسبة المئوية لفقرات الأداة؛ وقد تم تناول كل محور على حدات على الماته النحو التالي:

1. النتائج المتعلقة بالمحور الأول (درجة تو افر المتطلبات التشريعية والتنظيمية) جدول (6): المتوسطات الحسابية والانحر افات المعيارية لدرجة تو افر المتطلبات التشريعية والتنظيمية في الإشراف التربوي من وجهة نظر المشرفين مرتبة تنازلياً

\begin{tabular}{|c|c|c|c|c|c|c|}
\hline التو افر & الرتبة & 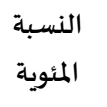 & المعياري - المراف & المستبط المتوسط & العبــــــــــــارات & م \\
\hline متوسطة & 1 & $\% 64$ & 0.604 & 1.92 & والمود قيم ومعتقدات مشتركة خاصية بثقافة تبادل المعرفة ونشرها لدى & 2 \\
\hline متوسطة & 2 & $\% 61.33$ & 0.668 & 1.84 & وضع الوزارة نظام محدد لإدارة المعرفة على كافة المستويات الإشرافية. & 4 \\
\hline 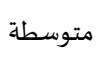 & 3 & $\% 61$ & 0.604 & 1.83 & توفير ثقافة منظميه داعمة لإدارة المعرفة بالوزارة & 1 \\
\hline 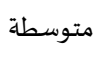 & 4 & $\% 59.67$ & 0.683 & 1.79 & توافر هيكل تنظيمي بالوزارة يساعد على تطبيق إدارة المعرفة. & 6 \\
\hline 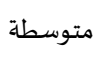 & 5 & $\% 57.33$ & 0.644 & 1.72 & توفير حزمة الوظائف الإدارية والمهنية الخاصة بإدارة المعرفة. & 7 \\
\hline 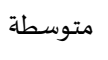 & 6 & $\% 56.33$ & 0.635 & 1.69 & وجود تشريع خاص لإدارة المعرفة على كافة المستويات. & 3 \\
\hline متوسطة & 7 & $\% 56$ & 0.656 & 1.68 & تلوفير وحدة إدارية متخصصية تزود الأقسام المختلفة بالبيانات والمعلومات & 12 \\
\hline 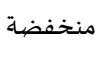 & 8 & $\% 52$ & 0.635 & 1.56 & تحديد آليات لتعاون الوزارة مع المنظمات الرائدة في إدارة المعرفة. & 9 \\
\hline 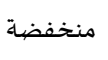 & 9 & $\% 52$ & 0.669 & 1.56 & بناء فرق عمل لتبادل المعرفة والخبرات والمهارات بين المشرفين. & 10 \\
\hline 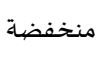 & 10 & $\% 52$ & 0.576 & 1.56 & توافر نظام تحفيز لاستقطاب الكفاءات المتميزة من خارج الوزارة. & 5 \\
\hline 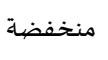 & 11 & $\% 44.33$ & 0.567 & 1.33 & توافر قسم خاص لحفظ الملكية الفكرية للمشرفين. & 13 \\
\hline 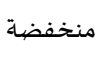 & 12 & $\% 43.67$ & 0.541 & 1.31 & إنشاء مراكز إبداع معرفي داخل الوحدات الإدارية بالإشراف التربوي. & 8 \\
\hline 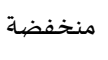 & 13 & $\% 41.33$ & 0.502 & 1.24 & توافر قسم خاص للاستشارات المعرفية. & 11 \\
\hline منخفضية & & $\% 53.67$ & 0.399 & 1.61 & المتطلبات التشريعية والتنظيمية ككل & \\
\hline
\end{tabular}

يتبين من الجدول (6) أن المتوسطات الحسابية لفقرات محور المتطلبات التشريعية والتنظيمية تراوحت بين (1.24 - 1.92)؛ وبنسبة مئوية تراوحت

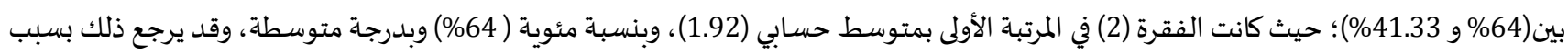

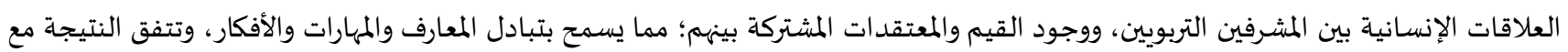
دراسة شالماني وتوراني (Shalmani \& Toorani, 2016) بأنه لتحقيق أقصى استفادة من الموارد البشرية والمادية؛ لابد من إنشاء وتوليد الفضياء الاجتماعي

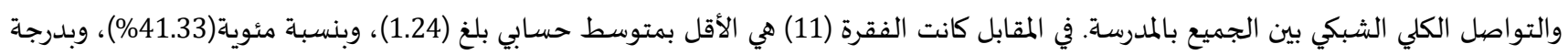
منخفضاة، وقد يعزى ذلك لعدم وجود مثل هذا القسم، يكون معنياً بصورة مباشرة بالاستشارات المعرفية في الهيكل التنظيمي الخاص بالمديرية العامة للموارد البشرية، أما المستوى العام لمحور المتطلبات التشريعية والتنظيمية ككل فقد بلغ المتوسط الحسابي(1.61) ونسبة مئوية (53.67\%)؛ أي جاء 
بدرجة منخفضة، وقد يرجع السبب في ذلك إلى عدم وجود هيكل تنظيمي للمديرية العامة للموارد البشرية يتسم بالمرونة تتدفق فيه المعلومات في كل الاتجاهات، وقلة إعطاء الصلاحيات وتفويض السلطات بصورة كافية للمشرفين التربويين بالمدارس، وضعف عملية الاتصال بين المشرفين والإدارة العليا بالمديرية، وكذلك قلة إشراك المشرفين التربويين في صنع القرار واتخاذه، وقد اختلفت هذه النتيجة مع دراسة كروان ( 2017) التي أظهرت أن أثر المتطلبات

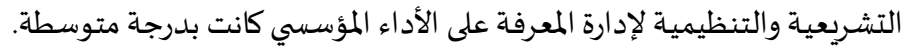

2. النتائج المتعلقة بالمحور الثاني (درجة تو افر المتطلبات الإدارية) جدول (7): المتوسطات الحسابية والانحر افات المعيارية لدرجة تو افر المتطلبات الإدارية في الإشراف التربوي من وجهة نظر المشرفين مرتبة تنازلياً

\begin{tabular}{|c|c|c|c|c|c|c|}
\hline 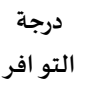 & 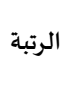 & 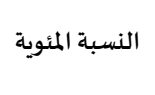 & 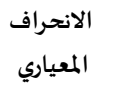 & الحسابي & 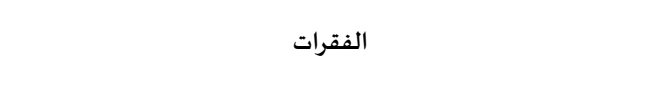 & م \\
\hline 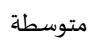 & 1 & $\% 60.67$ & 0.724 & 1.82 & اعتماد نظام ملمراقبة جودة الممارسات المتنوعة للمشرفين. & 11 \\
\hline 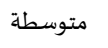 & 2 & $\% 55.67$ & 0.723 & 1.67 & عقد اللقاءات والاجتماعات الدورية لتشارك المعرفة بين المشرفين. & 10 \\
\hline 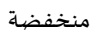 & 3 & $\% 55$ & 0.705 & 1.65 & دعم الوزارة للعلاقات الإنسانية بين المشرفين. & 5 \\
\hline منخفضة & 4 & $\% 55$ & 0.681 & 1.65 & قورية. & 7 \\
\hline منخفضية & 5 & $\% 53.33$ & 0.681 & 1.60 & وضع خطة واضحة لتطبيق إدارة المعرفة في الوزارة ومديرياتها & 1 \\
\hline 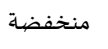 & 6 & $\% 53$ & 0.631 & 1.59 & الاهتمام بالأفكار والمقترحات التي يقدمها المشرفون. & 4 \\
\hline 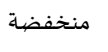 & 7 & $\% 51.33$ & 0.628 & 1.54 & تطوير عدد من المؤشرات لتقييم الإنتاج المعرفي لدى المشرفين التربويين & 9 \\
\hline منخفضية & 8 & $\% 49.67$ & 0.629 & 1.49 & العمل الإشرافي. & 2 \\
\hline 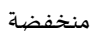 & 9 & $\% 49.67$ & 0.638 & 1.49 & وجود آلية( نظام) لتقييم المعرفة الموجودة لدى المشرفين والاحتفاظ بها. & 8 \\
\hline 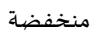 & 10 & $\% 45$ & 0.553 & 1.35 & بناء استراتيجية لاستثمار رأس المال الفكري لتطوير العمل الإشرافي. & 6 \\
\hline 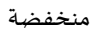 & 11 & $\% 43.33$ & 0.559 & 1.30 & توافر حوافز لتشجيع الابتكار والإبداع لدى المشرفين. & 3 \\
\hline 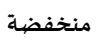 & & $\% 52$ & 0.457 & 1.56 & 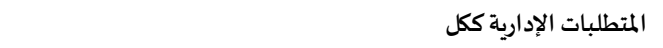 & \\
\hline
\end{tabular}

يتضح من الجدول (7) أن المتوسطات الحسابية لفقرات محور المتطلبات الإدارية جاءت بين (1.30 - 1.82) وبنسب مئوية تراوحت بين (60.67 \%

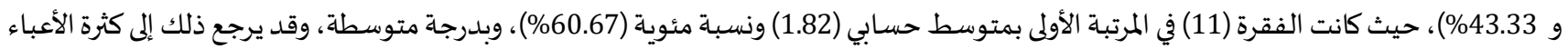

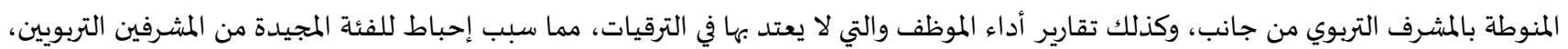
وبالتالي انعكس سلباً عليهم؛ فضعفت رغبتهم في تحسين وتنويع ممارساتهم الإشرافية، وقد اتفقت النتيجة مع دراسة شاهين (2015)؛ حيث أظهرت أن إنهات

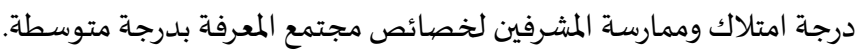
في المقابل كانت الفقرة (3) هي الأقل بمتوسط حسابي بلغ (1.30)، ونسبة مئوية بلغت (43.33\%) وبدرجة منخفضية، وقد يعود السبب في ذلك إلى قلة وعي المشرفين التربويين بأهمية المبادرات التربوية، وعدم تلقيهم التدريب المناسب واللازم لتكون جزءاً من ثقافة العمل لديهم رغم توفر البيئة المحفزة

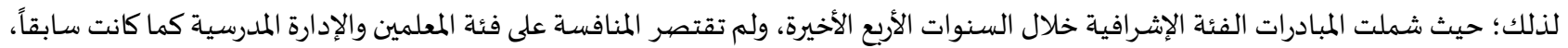
واتفقت النتيجة مع دراسة مكنيل( McNeil, 2011 في قلة توافر الالتزام اتجاه المبادرات، وقلة الموارد المالية والتكنولوجية، وندرة الحوافز والمكافآت،

والمفاهيم الخاطئة اتجاه الاستدامة.

أما بالنسبة لدرجة محور المتطلبات الإدارية ككل؛ فقد جاء بدرجة منخفضة؛؛ حيث بلغ المتوسط الحسابي( 1.56)، ونسبة مئوية(52\%)، وقد ويرجع ذلك إلى قلة عدد المشرفين التربويين وعدم تناسبه مع أعداد المعلمين بالمدارس الحكومية، مما أدى إلى انخفاض جودة الخدمة الإشرافية، وعدم اعتماد

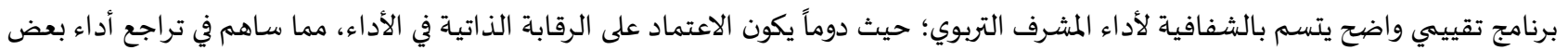

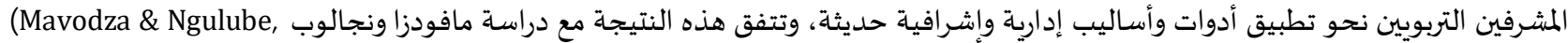

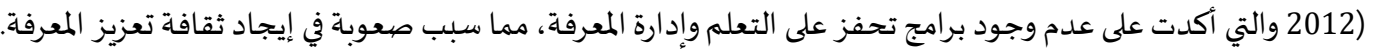


3. النتائج المتعلقة بالمحور الثالث (درجة تو افر المتطلبات البشرية)

جدول (8): المتوسطات الحسابية والانحر افات المعيارية لدرجة تو افر المتطلبات البشرية في الإشراف التربوي من وجهة نظر المشرفين مرتبة تنازلياً

\begin{tabular}{|c|c|c|c|c|c|c|}
\hline التو افر & 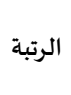 & النسبة المئوية & 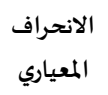 & المتوسط المسابي & العبــــــــارات & p \\
\hline 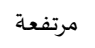 & 1 & $\% 79.33$ & 0.709 & 2.38 & استعداد المشرفين لتبادل المعرفة مع الآخرين. & 3 \\
\hline 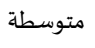 & 2 & $\% 77.33$ & 0.656 & 2.32 & تحمل المشرفين مسؤولية تطوير أنفسهم مهنيا. & 4 \\
\hline 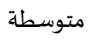 & 3 & $\% 75.33$ & 0.694 & 2.26 & مشاركة المشرفين في فرق العمل مختلفة المستويات. & 5 \\
\hline متوسطة & 4 & $\% 68.67$ & 0.693 & 2.06 & اطلاع المشرفين على المعارف الجديدة في التخصص. & 2 \\
\hline متوسطة & 5 & $\% 60$ & 0.697 & 1.80 & وجود الوعي الكافي بإدارة المعرفة وفوائدها لدى المشرفين. & 7 \\
\hline 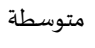 & 6 & $\% 58.33$ & 0.674 & 1.75 & حث المشرفين التربويين على اظهار معرفتهم الضمنية. & 13 \\
\hline 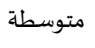 & 7 & $\% 56.33$ & 0.687 & 1.69 & توافر الحماس لدى المشرفين في مجال البحث العلمي & 1 \\
\hline 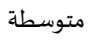 & 8 & $\% 56$ & 0.681 & 1.68 & استخدام البحث العلمي لتوليد المعرفة الجديدة المرتبطة بالعمل. & 6 \\
\hline 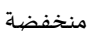 & 9 & $\% 54$ & 0.636 & 1.62 & تبادل الخبرات الناجحة في اجراء البحوث بين المشرفين. & 8 \\
\hline 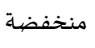 & 10 & $\% 53.33$ & 0.705 & 1.60 & احتفاظ الوزارة بالمشرفين الذين يسهمون في بناء المعرفة وتشاركها. & 14 \\
\hline 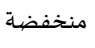 & 11 & $\% 53$ & 0.631 & 1.59 & تزويد المشرفين بالخبرات والمهارات اللازمة لإدارة المعرفة لدى المشرفين. & 11 \\
\hline 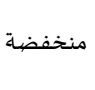 & 12 & $\% 52.67$ & 0.625 & 1.58 & المشرفين. جو من الثقة المتبادلة والانفتاح داخل الوزارة مما يعزز من تطوير المعارف لدى & 12 \\
\hline 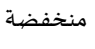 & 13 & $\% 52.33$ & 0.685 & 1.57 & توفير برامج للتنمية المهنية للمشرفين في ادارة المعرفة. & 10 \\
\hline 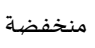 & 14 & $\% 52$ & 0.652 & 1.56 & تشجيع المشاركة في المعرفة من خلال إعداد البحوث العلمية بين التخصصيات المختلفة. & 9 \\
\hline 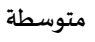 & & $\% 60.67$ & 0.441 & 1.82 & المتطلبات البشرية ككل & \\
\hline
\end{tabular}

يتضح من الجدول (8) أن المتوسطات الحسابية لفقرات محور المتطلبات البشرية تراوحت بين (1.56-2.38) وبنسبة مئوية تراوحت بين (79.33\%

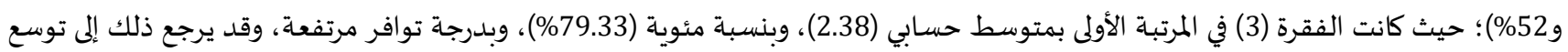
الثقافة المعلوماتية للمشرفين التربويين بسبب توظيف الحواسيب والتواصل الإلكتروني الشبكي المشترك، وكذلك توظيف البوابة التعليمية في إعداد

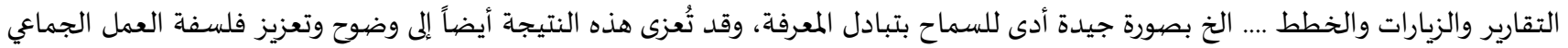
لتبادل الأفكار والخبرات بين المشرفين التربويين، وكذلك تشجيع بعض المشرفين على توليد الأفكار الابتكارية، ومشاركة المعرفة وتطوراتها من خلال

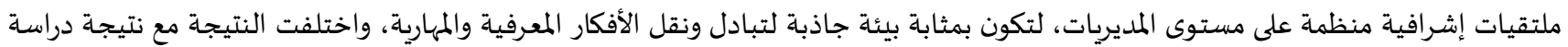
محمد وجوس (Mohammed \& Jose, 2016) في أن هناك حاجة في المجال التربوي لزيادة القوة الفكرية المتاحة داخل المؤسسة لتبادل الخبرات المختلفة. في المقابل كانت الفقرة (9) هي الأقل بمتوسط حسابي بلغ (1.56)، وبنسبة مئوية(52\%)، وبدرجة منخفضية، وقد يرجع السبب في ذلك إلى عدم

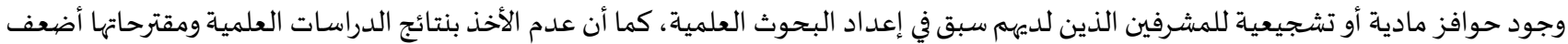
قيمة البحوث لدى المشرفين، وكذلك كثرة الأعباء الإدارية والفنية وزيادة المدارس وعدد المعلمين في المدرسة الواحدة التي يشرف عليه المشرف الواحد

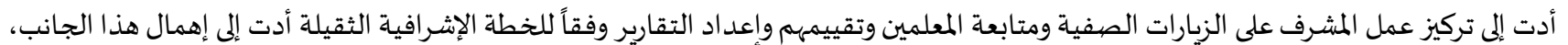
وقد اتفقت النتيجة مع دراسة مافودزا ونجالوب (Mavodza \& Ngulube, 2012) والتي توصلت إلى أهمية التركيز على ايجاد مناخ تكنولوجي يدعم عملية التعلم والتعليم وأنشطة البحث العلمي، وقد جاء محور المتطلبات البشرية ككل بدرجة متوسطة؛ حيث بلغ المتوسط الحسبابي (1.82) ونسبة مئوية (60.67\%)، وهذا يعود إلى ضرورة تعزيز عدد المشرفين التربويين ووضع عدد محدود من المدراس للإشراف عليها، والتركيز على التحفيز للمشرف المجيد،

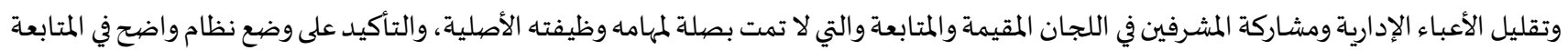
والرقابة لأداء المشرفين التربويين. 
4. النتائج المتعلقة بالمحور الر ابع (درجة تو افر المتطلبات المادية والتكنولوجية) جدول (9): المتوسطات الحسابية والانحر افات المعيارية لدرجة تو افر المتطلبات المادية والتكنولوجية في الإشراف التربوي من وجهة نظر المشرفين مرتبة تنازلياً

\begin{tabular}{|c|c|c|c|c|c|c|}
\hline 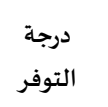 & 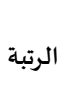 & 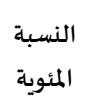 & 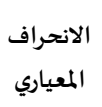 & الحسبابي - المتوسط & 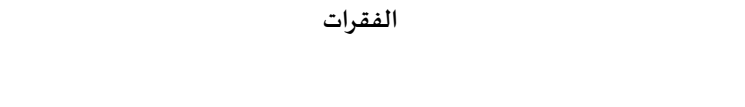 & r \\
\hline 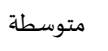 & 1 & $\% 71$ & 0.796 & 2.13 & توفير نظام الكتروني لإعداد التقارير في مجال الإشراف التربوي. & 7 \\
\hline 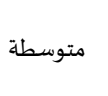 & 2 & $\% 67$ & 0.753 & 2.01 & والوحير شبكة اتصالات داخلية وخارجية بين الوزارة والمديريات والدوائر والاقسام & 4 \\
\hline 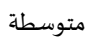 & 3 & $\% 56.67$ & 0.691 & 1.70 & نشر الموقع الإلكتروني بالوزارة للممارسات الأفضل المتعلقة بإدارة المعرفة. & 3 \\
\hline 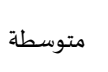 & 4 & $\% 56$ & 0.697 & 1.68 & توفير البحوث والدراسات في مكتبات الوزارة ودوائر التدربب لتطوير العمل الإشرافي. & 12 \\
\hline منخفضية & 5 & $\% 55.33$ & 0.702 & 1.66 & والإلكترونية وأنظمة الدعم الاجتماتي. تكنوليه تساعد على التشارك المعرفي مثل منتديات المناقشة & 9 \\
\hline 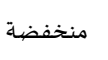 & 6 & $\% 54$ & 0.686 & 1.62 & توفير نظام فعال للبيانات والمعلومات الإشرافية (يتميز بالدقة والحداثة والسرعة). & 13 \\
\hline 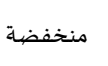 & 7 & $\% 52.33$ & 0.701 & 1.57 & وجود موقع الكتروني للمشرفين التربويين لتبادل الأفكار والمعرفة والخبرات. & 5 \\
\hline 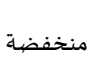 & 8 & $\% 50$ & 0.629 & 1.50 & وجود نظام دائم لصيانة موجودات المعرفة والمحافظة عليها. & 10 \\
\hline 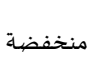 & 9 & $\% 47.67$ & 0.616 & 1.43 & توفير البنية التحتية لإدارة المعرفة على كافة المستويات الإشرافية. & 2 \\
\hline 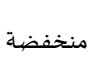 & 10 & $\% 47.33$ & 0.624 & 1.42 & انشاء قاعدة بيانات بالأبحاث التي يجرهيا المشرفون. & 11 \\
\hline 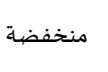 & 11 & $\% 45.67$ & 0.616 & 1.37 & إصدار مجلة دورية خاصة بالأبحاث والأوراق العلمية التي ينجزها المشرفون. & 1 \\
\hline 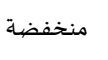 & 12 & $\% 45.67$ & 0.569 & 1.37 & 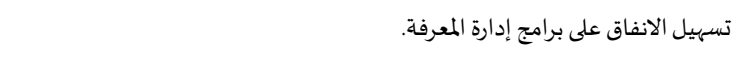 & 14 \\
\hline 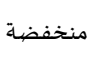 & 13 & $\% 44.33$ & 0.568 & 1.33 & وجود نظام للحوافز لتشجيع فرق العمل التي تقوم بأجراء البحوث والمشاريع المشتركة. & 8 \\
\hline 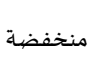 & 14 & $\% 41.67$ & 0.515 & 1.25 & وجود مصادر لتمويل البحوث والمشاريع المشتركة في العمل الإشرافي. & 6 \\
\hline 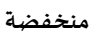 & & $\% 52.33$ & 0.440 & 1.57 & 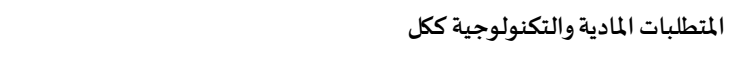 & \\
\hline
\end{tabular}

يتبين الجدول (9) أن المتوسطات الحسابية لفقرات محور المتطلبات المادية والتكنولوجية تراوحت بين (1.25- 2.13) وبنسبة مئوية تراوحت بين

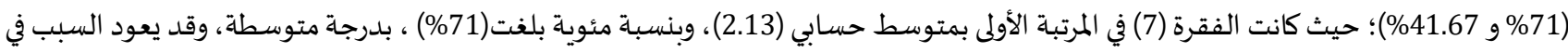

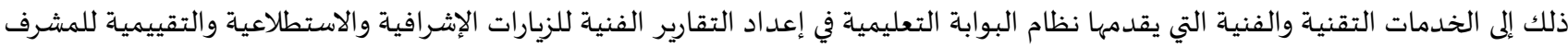

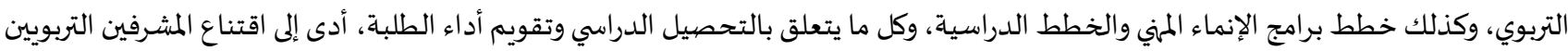

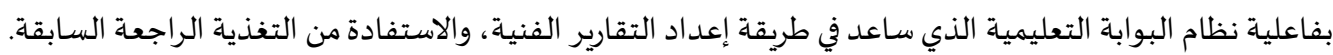

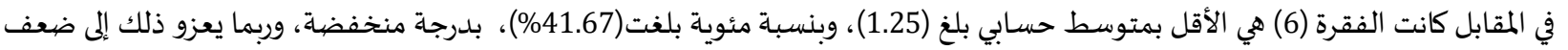
وجود مخصصات مالية لإعداد البحوث من قبل الوزارة، واقتصار هذا الدور على مجلس البحث العلمي، وتمويل بعض المؤسسات الحكومية والخاصية، والتي تكون قليلة ومحصورة على نوعية معينة من البحوث، وقد اتفقت النتيجة مع دراسة (Mavodza, and Ngulube 2012) بضرورة مندوة الاهتمام بإيجاد مناخ تكنولوجي يدعم عملية التعلم والتعليم وأنشطة البحث العلمي، أما مستوى محور المتطلبات المادية والتكنولوجية ككل جاء بمستوى منخفض؛

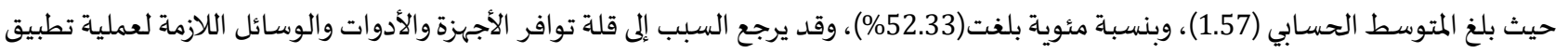
إدارة المعرفة للمشرفين التربويين، وعدم توفر قاعات ببعض المدارس تكون خاصة بالمشرفين التربويين، تتوفر بها كافة الخدمات والمتطلبات المادية

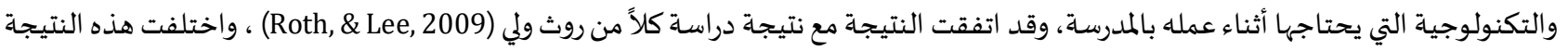
مع دراسة كروان (2017) التي جاء مجال تكنولوجيا المعلومات فيها بمستوى مرتفع. 
ثانياً: النتائج المتعلقة بالسؤال الثاني: "ما درجة أهمية متطلبات توظيف إدارة المعرفة في الإشراف التربوي بسلطنة عمان من وجهة نظر المشرفين"؟ للإجابة عن هذا السؤال، تم استخراج المتوسطات الحسابية والانحرافات المعيارية والنسب المئوية لاستجابات عينة الراسة وكانت النتائج كما في جدول (10)، والجدول التالي يوضح ذلك: هندو جدول (10): المتوسطات الحسابية والانحر افات المعيارية والنسب المئوية لدرجة أهمية متطلبات إدارة المعرفة في الإشراف التربوي من وجهة نظر المشرفين

\begin{tabular}{|c|c|c|c|c|c|c|}
\hline درجة الأهمية & 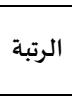 & المئوية & الانحراف المعياري & المتوسط الحسابي & المحور & r \\
\hline 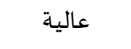 & 4 & $\% 85.6$ & 0.515 & 2.57 & المتطلبات التشريعية والتنظيمية & 1 \\
\hline 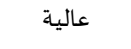 & 3 & $\% 87$ & 0.545 & 2.62 & المتطلبات الإدارية & 2 \\
\hline 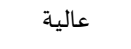 & 1 & $\% 89.6$ & 0.493 & 2.69 & المتطلبات البشرية & 3 \\
\hline عالية & 2 & $\% 88.6$ & 0.532 & 2.66 & المتطلبات المادية والتكنولوجية & 4 \\
\hline عالية & & $\% 88$ & 0.488 & 2.64 & الدرجة الكلية & \\
\hline
\end{tabular}

يتضح من الجدول (10) أن المتوسطات الحسابية لاستجابات المشرفين تراوحت بين (2.57- 2.69)، وبنسب مئوية تباينت ما بين (85.6\% -

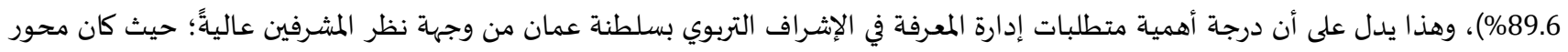

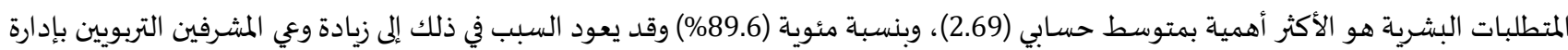
المعرفة وفوائدها، وأن قياس فعالية تطبيق إدارة المعرفة يعتمد على قدرة العنصر البشري والكفاءات الإشرافية، وأن المتطلبات البشرية هي أحد المقومات

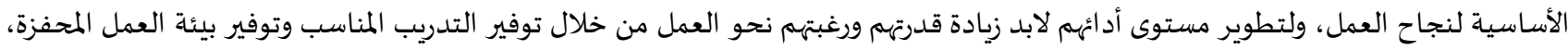

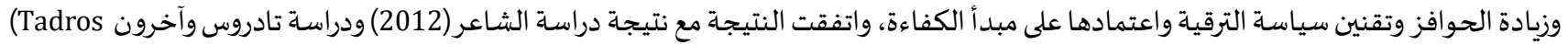

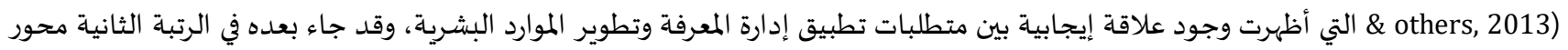

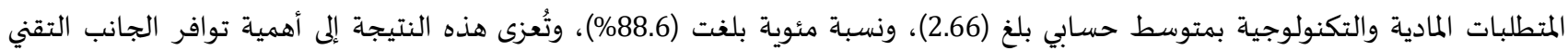

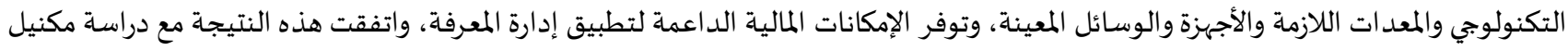
(McNeil, 2011) بينما جاء محور المتطلبات الإدارية في المرتبة الثالثة من حيث الأهمية بمتوسط حسابي (2.62)، وبنسبة مئوية بلغت (87\%)، وقدابة وقد يعزى إلى عدم

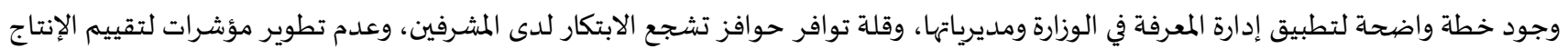
المعرفي لهمجم

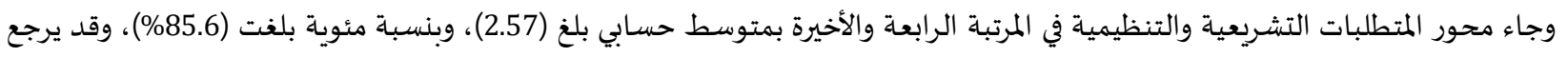

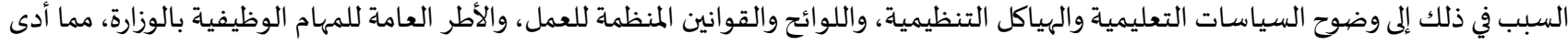
إلى أن تكون الأهمية لهذا المحور الأخيرة، واختلفت النتيجة مع نتيجة دراسـة الطويس (2017) التي أكدت على ضرورة تطوير أدوار ومهام الإشراف والتشريعات المنظمة له.

ثالثاً: النتائج المتعلقة بالسؤال الثالث: "هل توجد فروق ذات دلالة إحصائية (0.05 $\alpha$ ف في درجة تو افرمتطلبات تطبيق إدارة المعرفة وأهميتها من

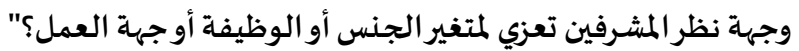
للإجابة عن السؤال تم استخد ام اختبار "ت" لعينتين مستقلتين وكذلك تحليل التباين الأحادي ONE WAY ANOVA، وقد تم عرض النتائج المتعلقة بالسؤال على النحو التالي: 1. النتائج المتعلقة بدرجة تو افرمتطلبات تطبيق إدارة المعرفة وأهميتها تبعاً لمتغير الجنس: للوقوف على دلالة الفروق في درجة توافر متطلبات تطبيق إدارة المعرفة وأهميتها تبعاً لمتغير الجنس تم استخدام اختبار (ت) لعينتين مستقلتين، وكانت النتائج كما في جدول (11). 
جدول (11): نتائج اختبار (ت) لدلالة الفروق في درجة تو افرمتطلبات تطبيق إدارة المعرفة وأهميتها تبعاً لمتغير الجنس

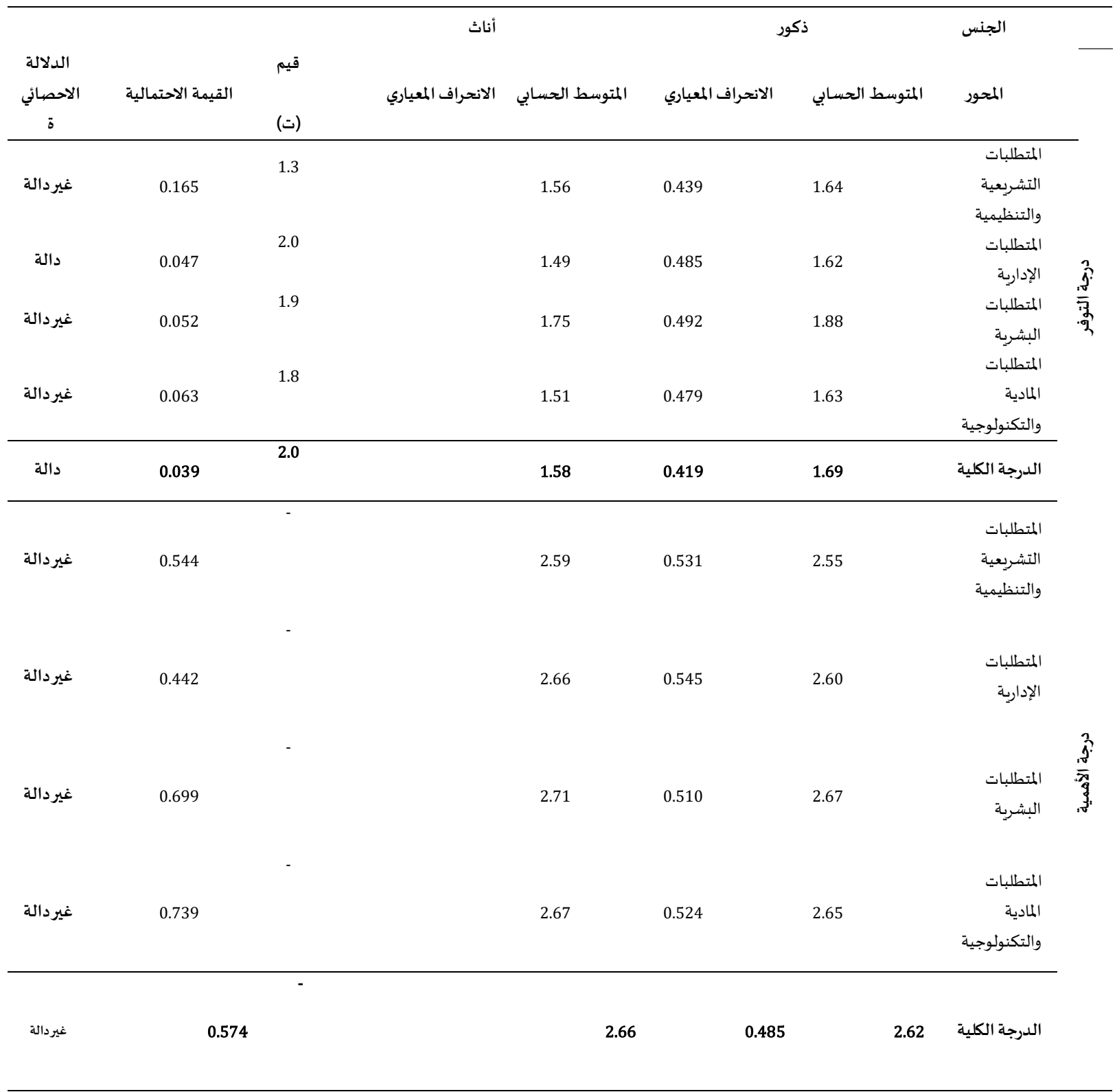

يتضح من الجدول (11) عدم وجود فروق ذات دلالة إحصائية في تقديرات عينة المشرفين لدرجة توافر متطلبات توظيف إدارة المعرفة، ودرجة

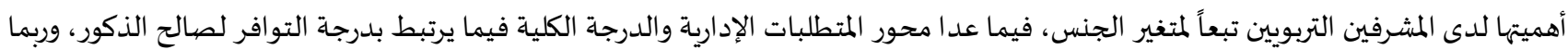

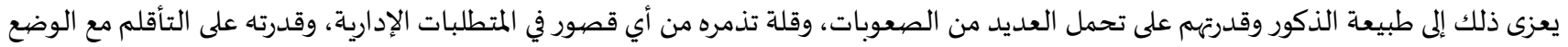

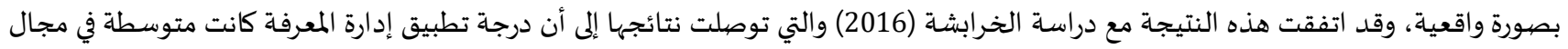
إدراك دور إدارة المعرفة، وأن هناك فروق ذات دلالة إحصائية لصالح الذكور، كما اختلفت هذه النتيجة مع دراسة الحبسية (2012) التي أظهرت نتائجها عدم وجود فروق دالة إحصائياً تعزى لمتغير الجنس.

2. النتائج المتعلقة بلدرجة تو افرمتطلبات تطبيق إدارة المعرفة وأهميتها تبعاً لمتغير مكان/ جهة العمل (الوزارة / المديرية) للوقوف على دلالة الفروق في درجة توافر متطلبات تطبيق إدارة المعرفة وأهميتها تبعاً لمتغير مكان العمل تم استخدام اختبار (ت) والجدول (12) يبين نتائج التحليل: 
جدول (12): نتائج اختبار(ت) لدلالة الفروق في درجة تو افر متطلبات تطبيق إدارة المعرفة وأهميتها تبعاً لمتغير مكان/ جهة العمل

\begin{tabular}{|c|c|c|c|c|c|c|c|c|}
\hline \multirow[b]{2}{*}{ الاحصبائية } & \multirow[b]{2}{*}{ الاحتمالية } & \multirow[b]{2}{*}{ قيمة (ت) } & \multicolumn{2}{|c|}{ المديرية } & \multicolumn{2}{|c|}{ الوزارة } & \multirow[t]{2}{*}{ مكان العمل } & \multirow[t]{2}{*}{ م } \\
\hline & & & المعياري & الحسابي & المعياري & الحتوسط & & \\
\hline غير دالة & 0.216 & 1.242 & 0.393 & 1.59 & 0.466 & 1.73 & المتطلبات التشريعية & \\
\hline دالة & 0.043 & 2.039 & 0.449 & 1.54 & 0.490 & 1.79 & المتطلبات الإدارية & \\
\hline غير دالة & 0.065 & 1.860 & 0.438 & 1.799 & 0.437 & 2.02 & المتطلبات البشرية & 3 \\
\hline غير دالة & 0.371 & 0.989 & 0.445 & 1.57 & 0.382 & 1.67 & المتطلبات المادية & 3 \\
\hline غير دالة & 0.083 & 1.742 & 0.377 & 1.62 & 0.382 & 1.80 & الدرجة الكلية & \\
\hline غير دالة & 0.959 & 0.051 & 0.524 & 2.57 & 0.423 & 2.57 & والمتطلبات التشريعية & \\
\hline غير دالة & 0.823 & 0.224 & 0.558 & 2.62 & 0.395 & 2.65 & المتطلبات الإدارية & $\hat{\imath}$ \\
\hline غير دالة & 0.609 & 0.513 & 0.507 & 2.69 & 0.288 & 2.76 & المتطلبات البشرية & 离 \\
\hline غير دالة & 0.929 & $0.089-$ & 0.545 & 2.66 & 0.372 & 2.648 & المتطلبات المادية & \\
\hline غير دالة & 0.857 & 0.181 & 0.502 & 2.635 & 0.319 & 2.66 & الدرجة الكلية & \\
\hline
\end{tabular}

يتضح من الجدول رقم (12) أن القيمة الاحتمالية لجميع المحاور أعلى من مستوى الدلالة (0.05) )، مما يدل ذلك على على عدم وجود فروق ذات

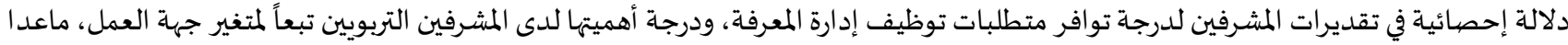

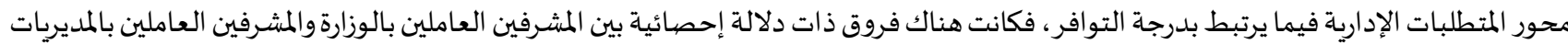

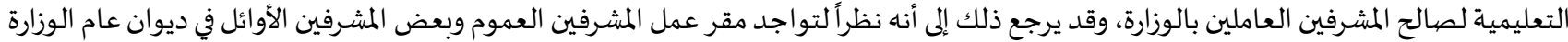

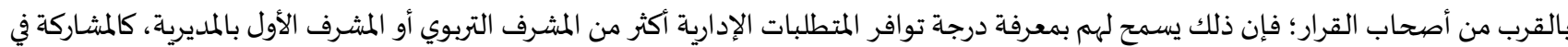

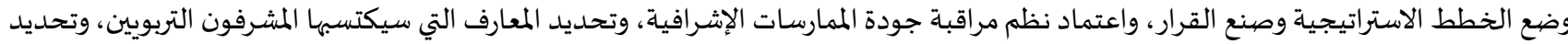

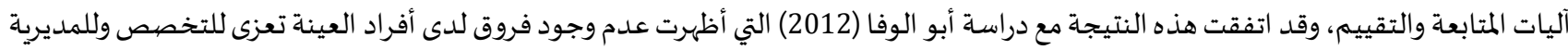
التابع لها، واختلفت النتيجة مع دراسة المنصوري(2011) التي أظهرت وجود فروق حول درجة تطبيق عمليات إدارة المعرفة في جامعة السلطان قابوس المانس

3. النتائج المتعلقة بدرجة تو افرمتطلبات تطبيق إدارة المعرفة وأهميتها تبعاً لمتغير الوظيفة (مشرف عام- مشرف أول- مشرف تربوي)

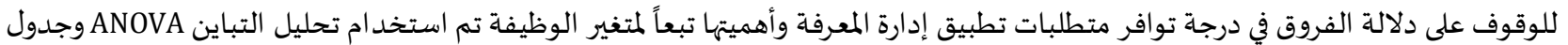

\begin{tabular}{|c|c|c|c|c|c|c|c|c|}
\hline الدلالة & الدلالة & ف & متوسط المربعات & الحربة & مجموع المربعات & مصادر التباين & الأبعاد & المحاور \\
\hline \multirow{3}{*}{ غإئياً } & \multirow{3}{*}{0.184} & \multirow{3}{*}{1.708} & 0.271 & 2 & 0.542 & بين المجموعات & \multirow{3}{*}{ المتطلبات التشريعية } & \multirow{7}{*}{ 旁 } \\
\hline & & & \multirow[t]{2}{*}{0.159} & 178 & 28.251 & المجموعات & & \\
\hline & & & & 180 & 28.793 & التباين الكلي & & \\
\hline \multirow{3}{*}{ إحصائياً } & \multirow{3}{*}{0.019} & \multirow{3}{*}{4.077} & 0.823 & 2 & 1.646 & بين المجموعات & \multirow{3}{*}{ المتطلبات الإدارية } & \\
\hline & & & \multirow[t]{2}{*}{0.202} & 178 & 35.938 & المجموعات & & \\
\hline & & & & 180 & 37.584 & التباين الكلي & & \\
\hline غير دائياً & 0.184 & 1.712 & 0.193 & 178 & 34.323 & بين المجموعات & المتطلبات البشرية & \\
\hline
\end{tabular}




\begin{tabular}{|c|c|c|c|c|c|c|c|c|}
\hline & & & & 180 & 34.983 & التباين الكلي & & \\
\hline \multirow{4}{*}{ غير دالة } & \multirow{4}{*}{0.624} & \multirow{4}{*}{0.473} & 0.092 & 2 & 0.184 & بين المجموعات & \multirow{4}{*}{ والمتكلبات المادية } & \\
\hline & & & \multirow{3}{*}{0.194} & & & داخل & & \\
\hline & & & & 178 & 34.611 & المجموعات & & \\
\hline & & & & 180 & 34.795 & التباين الكلي & & \\
\hline \multirow{3}{*}{ غير دالة } & \multirow{3}{*}{0.110} & \multirow{3}{*}{2.239} & 0.318 & 2 & 0.636 & ين المجمموعات & \multirow{3}{*}{ الدرجة الكلية } & \\
\hline & & & \multirow[t]{2}{*}{0.142} & 178 & 25.265 & المجموعات & & \\
\hline & & & & 180 & 25.900 & التباين الكلي & & \\
\hline \multirow{3}{*}{ إحصير دالةً } & \multirow{3}{*}{0.582} & \multirow{3}{*}{0.542} & 0.145 & 2 & 0.289 & بين المجموعات & \multirow{3}{*}{ المتطلبات التشريعية } & \\
\hline & & & \multirow{2}{*}{0.267} & 178 & 47.455 & داخل & & \\
\hline & & & & 180 & 47.744 & التباين الكلي & & \\
\hline \multirow{3}{*}{ غير دالة } & \multirow{3}{*}{0.331} & \multirow{3}{*}{1.112} & 0.330 & 2 & 0.660 & بين المجموعات & \multirow{3}{*}{ المتطلبات الإدارية } & \\
\hline & & & \multirow[t]{2}{*}{0.297} & 178 & 52.850 & المجموعات & & \\
\hline & & & & 180 & 53.511 & التباين الكلي & & \\
\hline \multirow{4}{*}{ غير دالة } & \multirow{4}{*}{0.345} & \multirow{4}{*}{1.071} & 0.260 & 2 & 0.520 & بين المجموعات & \multirow{4}{*}{ المتطلبات البشرية } & \\
\hline & & & \multirow{3}{*}{0.243} & 178 & 12165 & داخل & & $\frac{5}{2}$ \\
\hline & & & & 170 & 75.100 & المجموعات & & s. \\
\hline & & & & 180 & 43.685 & التباين الكلي & & \\
\hline \multirow{4}{*}{ غير دالة } & \multirow{4}{*}{0.579} & \multirow{4}{*}{0.548} & 0.156 & 2 & 0.312 & بين المجموعات & \multirow{4}{*}{ والمتكلبات المادية } & \\
\hline & & & \multirow{3}{*}{0.285} & & & داخل & & \\
\hline & & & & 178 & 50.720 & المجموعات & & \\
\hline & & & & 180 & 51.032 & التباين الكلي & & \\
\hline \multirow{4}{*}{ غير دالة } & \multirow{4}{*}{0.448} & & 0.193 & 2 & 0.386 & يين المجموعات & & \\
\hline & & 0007 & גרכ & 170 & (1)โร & داخل & 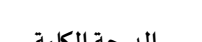 & \\
\hline & & 0.807 & 0.239 & 170 & 42.502 & المججموعات & الدمربجه الحية & \\
\hline & & & & 180 & 42.938 & التباين الكلي & & \\
\hline
\end{tabular}

يتضح من نتائج الجدول (13) عدم وجود فروق ذات دلالة إحصائية بين استجابات المشرفين في جميع المحاور وفق لدرجة التوافر، وكذلك درجة

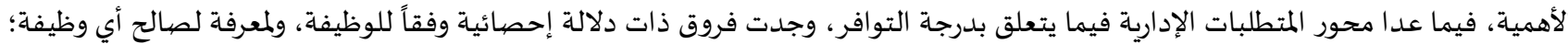

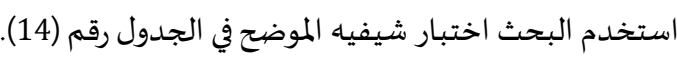
جدول (14): اختبارشافيه للمقارنات البعدية على درجة التو افر (محور المتطلبات الإدارية) وفقاً لمتغير الوظيفة

\begin{tabular}{|c|c|c|c|c|c|}
\hline مشرف تربوي & مشرف أول & مشرف عام & الوظيفة & المتوسط & الأبعاد \\
\hline \multirow[t]{3}{*}{ * } & & & مشرف عام & 2.09 & \\
\hline & & & مشرف أول & 1.73 & المتطلبات الإدارية \\
\hline & & * & مشرف تربوي & 1.53 & \\
\hline
\end{tabular}

يتضح من خلال الجدول أعلاه أن الفروق لمحور المتطلبات الإدارية حسب الوظيفة، تكون بين المشرف العام والمشرف التربوي لصالح المشرف

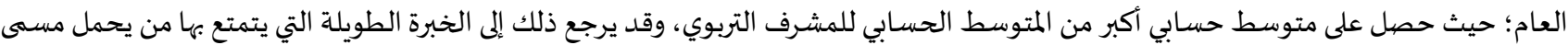

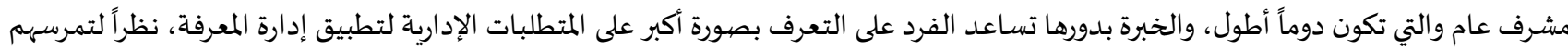
مجال العمل، وإلمامهم التام بالخطة الاستراتيجية التطويرية العامة للإشراف التربوي، وقد اختلفت مع دراسة المنصيوري (2011) التي أظهرت عدم وجود فروق ذات دلالة إحصائية في استجابات أعضاء هيئة التدريس بالجامعة، تعزى لأثر متغير الرتبة الأكاديمية.

توصيات البحث ومقترحاته:

$$
\text { في ضوء النتائج التي تم التوصل إلها البحث، فإن أهم ما يوصي باه البحث ويقترحه ما يلي: }
$$

أن تبدأ وزارة التربية والتعليم في وضيع الاستراتيجية المناسبة لتطبيق إدارة المعرفة بما يتفق والسياسة العامة لاستراتيجية عمان 2040م. 
عقد دورات متخصصة للمشرفين التربويين في كافة المديريات التعليمية في مجال إدارة المعرفة، وخاصة في البرامج التقنية التي تدعم النواحي الفنية كبرامج الفيديو كونفرنس لمتابعة تنفيذ المعلم للحصص بشكل مباشر، ومتابعة وتقييم مدى أهميتها في تطوير العمل الإشرافي، والتأكيد على تنمياة

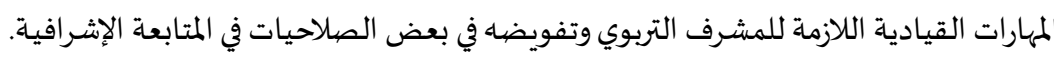
توفير المتطلبات المالية والتقنية لمساعدة المشرفين التربويين على تطبيق إدارة المعرفة، ووضع نظام حوافز ومسابقات مقننة تعزز المبادرات التربوية في مجال الإشراف التربوي، وإنشاء صندوق لدعم البحوث التربوية تحت إشراف وتمويل من وزارة التربية والتعليم. توفير قاعات ونظم اتصال حديثة وأجهزة، بحيث تكون إلزامية في كل مدرسة للمشرفين التربويين، وإنشاء قاعدة بيانات بحثية بوزارة التعليم

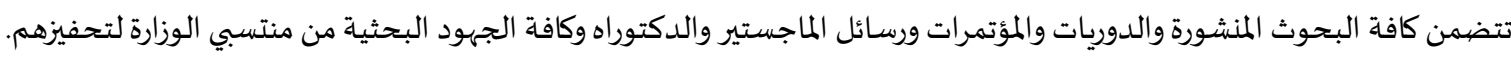
الاهتمام بإنشاء واستحداث وحدة خاصة مستقلة (قسم) تابعة للمديرية العامة للإشراف التربوي معني بتطبيق إدارة المعرفة. تشجيع المشرفين التربويين على البحث العلمي والاهتمام بتعزيزهم والاستفادة من نتاج دراساتهم لتحسين العملية الإشرافية وتطويرها.

معوقات إدارة المعرفة بمد ارس التعليم الأساسي في سلطنة عمان: دراسـة نوعية. استراتيجية مقترحة لتطبيق إدارة المعرفة في الإشراف التربوي بسلطنة عمان. إدارة المعرفة مدخل لتحقيق التميز الإداري بالمدارس العمانية.

المراجع:

أولاً: المراجع العربية:

1. أحمد، مطيعة؛ علي، نايفة؛ مغرقونة، أريج (2017).واقع تطبيق عمليات إدارة المعرفة في المدارس الثانوية وعلاقتها بأداء مدربسيها من وجهة نظهرهم

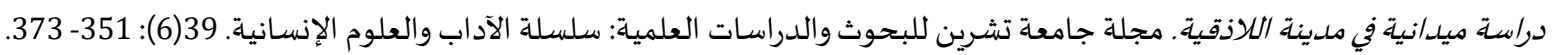
2. بدوي، أحمد زكي (1977). معجم مصيطلحات العلوم الاجتماعية. بيروت: مكتبة لبنان.

3. البطانية، محمد تركي؛ المشاقبة، زياد محمد (2010). اد/رة المعرفة بين النظرية والتطبيق. دار جليس الزمان للنشر والتوزيع. عمان. الأردن.

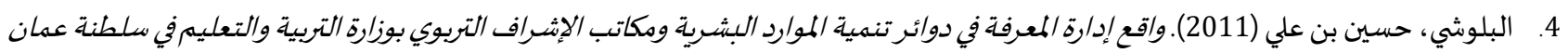

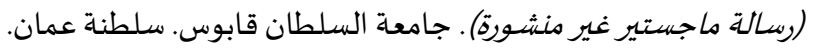
5. البلوشياة، فاطمة موسى (2013). دور الاقتصاد المعرفي في تطوير النظام التوبوي من وجهة نظر المشيرفين التوبويين (رسالة ماجستير غير منشورة). جامعة مؤتة. الاردن.

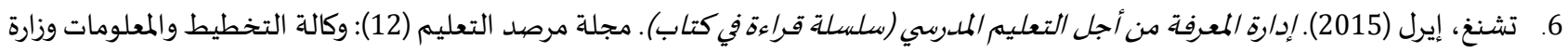
التعليم، الرياض، المملكة العربية السعودية. 7. التكريتي، سعد غالب ياسين (2004). نظم مساندة القرارات. عمان، دار المناهج للنشر والتوزيع.

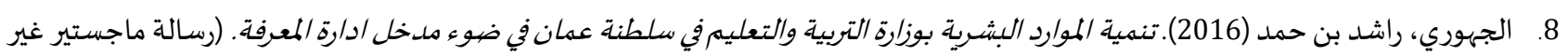
منشورة). جامعة السلطان قابوس. عمان. 9. حامد، محمد رؤوف (2006). إدارة المعرفة والابداع المجتمعي (ط3). الهيئة المصرية العامة للكتاب: مكتبة الاسرة. القاهرة.

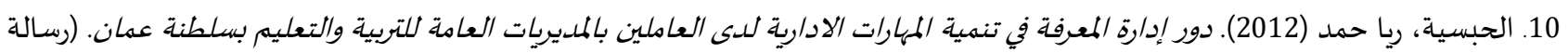
ماجستير غير منشورة)، جامعة نزوى. عمان.

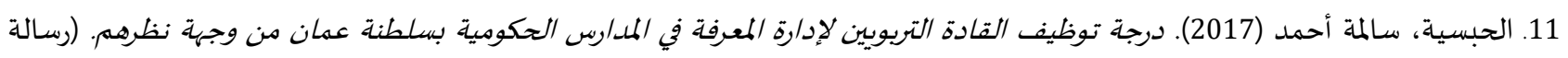

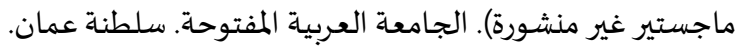
12. الحبوب، أسماء خلف (2010). دور ادارق المعرفة في تطوير أداء مراكز الإشراف التوبوي في ملدينة الرياض من وجهة نظر المشسفات التريويات (رسالة ماجستير غير منشورة). جامعة مؤتة. الاردن. 13. الحربي، عبد الله عواد (2012). دور المشـرف التريوي في تحقيق متطلبات مجتمع المعرفة في محافظة حفر الباطن. المؤتمر العلمي الثاني والعشرون

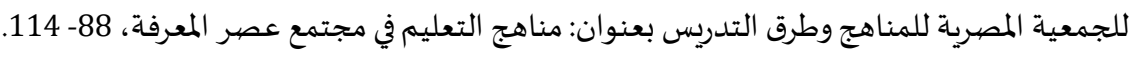


14. الحربي، فهد جهز (2015). أداء المشـرف التوبوي في ضهوء تطبيق متطلبات المجتمع المعرفي بإدارات التربية والتعليم بالمملكة العببية السعودية. مجلة كلية التربية (102)، 26.

15. الخرابشة، عمر محمد عبد الله (2016). درجة تطبيق إدارة المعرفة في جامعة البلقاء التطبيقية في الأردن من وجهة نظر أعضياء هيئها التدريسية. مجلة دراسات العلوم التربوية بالجامعة الأردنية. 43 (5):1829- 1853.

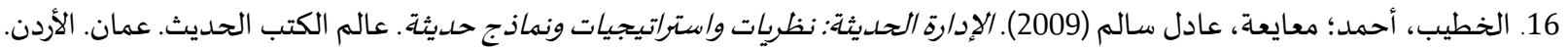
17. آل رحمة، هيفاء محسن (2017). متطلبات تطوير الإثـراف التوبوي في ضيوء التخطيط الاستراتيجي بسلطنة عمان (رسالة ماجستير غير منشورة). جامعة السلطان قابوس. سلطنة عمان. 18. الزامل، ريم(2003). إدارة المعرفة في مجتمع قادر على المنافسة. مجلة العالم الرقهي (16) [مجلة إلكترونية]، استرجع بتاريخ 30 مايو 2020 من موقع مuww.aljazirah.com

19. أبو زيد، أحمد (2005). المعرفة وصناعة المستقبل. مجلة العربي (61). الكويت.

20. الشاعر، عدلي داود (2012). اد/رة المعرفة مدخل لتطوير الإشراف التوبوي. مجلة البحث العلمي في التربية. 13(3): 1657- 1684. 21. شاهين، عبد الرحمن بن يوسف (2015). درجة /متلاك وممارسة كفايات الإشراف التويوي في ضوء خصيائص مجتمع المعرفة بمنطقة الملدينة المنورة.

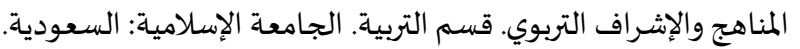
22. الشمراني، حامد محمد (2017). درجة ممارسة معلمي ومعلمات المدارس الثانوية في محافظة الدوادمي لعمليات إدارة المعرفة دراسة ميدانية. مجلة

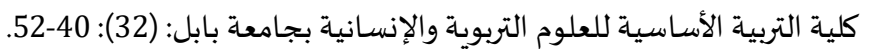
23. ضحاوي، بيومي محمد؛ المليجي، رضا إبراهيم (2010).توجهات الإدارة التويوية الفعالة في مجتمع المعرفة. دار الفكر العربي، القاهرة.

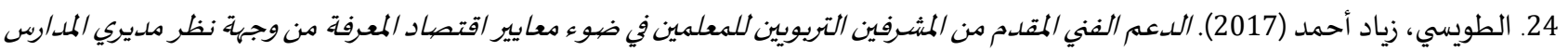
في الأردن. مجلة دراسات العلوم التربوية: 44(ملحق): 121 - 132.

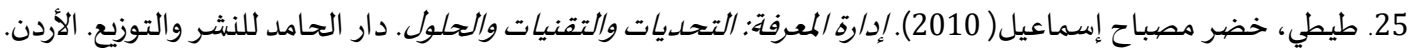
26. عبد الهادي، جودة عزت (2002). الإشـراف التريوي: مفاهيماه وأساليبه. عمان. الدار العلمية الدولية للنشر والتوزيع. 27. عبد الوهاب، سمير محمد (2006). متطلبات تطبيق إدارة المعرفة في الممدن العببية: دراسة حالة على مدينة القاهرة. الندوة الدولية لمدن المعرفة.

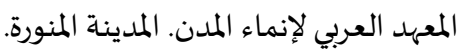
28. العلوياة، منى (2014). تصهور مقترح لتفعيل الإشـراف التويوي بمدارس التعليمر ما بعد الأساسي بمحافظة مستط في ضيوء نموذج الإشراف المتنوع. (رسالة ماجستير غير منشورة). جامعة نزوى. سلطنة عمان. 29. علي، أسامة محمد سيد (2013). إد/رة المعرفة، اتجاهات إدارية معاصرة ج (1). دار العلم الايمان للنشر والتوزيع. القاهرة. جمهورية مصر العربية.

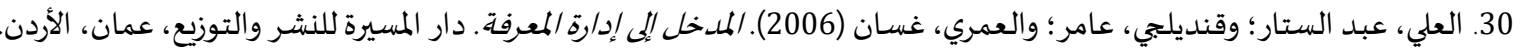
31. القاسمية، عايدة بنت بطي (2009). تصهور مقترح للتطوير الإد/ري بوزارة التربية والتعليم بسلطنة عمان في ضيوء إدارة المعرفة، . جامعة القاهرة. جمهورية مصر العربية. 32. القداح، محمد إبراهيم (2017). الحاجات المهنية لدى المشهفين التويويين في الأردن إلى الكفايات اللازهة لإدارة المعرفة في ضيوء مبادئ سينج للمنظمات المتعلمة . مجلة كلية التربية في العلوم التربوية: 41(3): 70- 111.

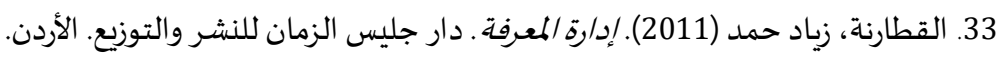
34. الكبيسي، صلاح الدين (2005). إدارة المعرفة. المنظمة العربية للتنمية الإدارية. القاهرة.

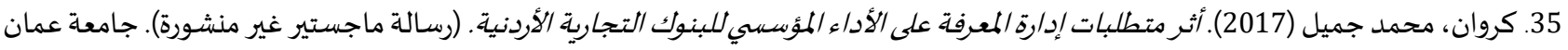
العربية. الأردن.

36. الكسباني، محمد (2012). البحث التربوي بين النظرية والتطبيق. دار الفكر العربي: القاهرة. 37. ملكاوي، ابراهيم الخلوف (2007). اد/رة المعرفة: الممارسات والمفاهيم. الوراق للنشر التوزيع. عمان. الأردن. 38. المنصوري (2011) . درجة تطبيق عمليات /دارة المعرفة في جامعة السلطان قابوس في سلطنة عمان من وجهة نظر أعضاء هيئة التدريس في الكليات العلمية والانسانية التابعة لها. جامعة اليرموك. الاردن.

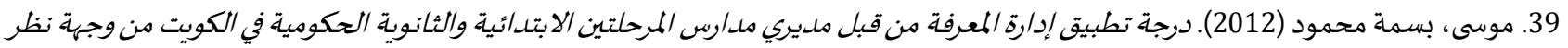
المديرين والموجهين الفنيين (رسالة ماجستير غير منشورة). قسم الإدارة والقيادة التربوية. جامعة الشرق الأوسط. الكويت. ملسئ. 


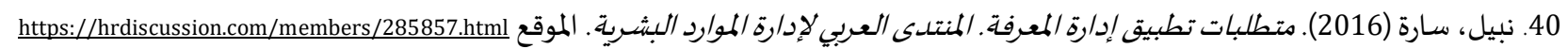

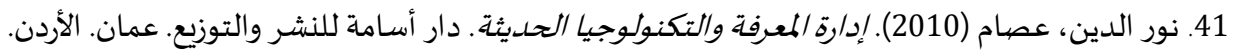

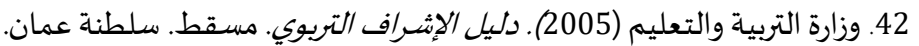

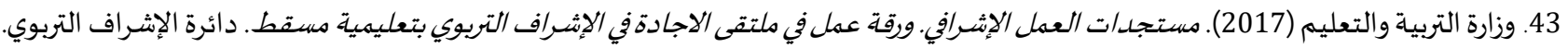

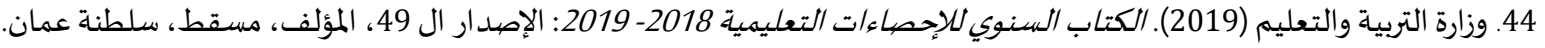

45. أبو الوفا، أيمن علي (2012). واقع إدارة المعرفة في الإثراف التربوي بالمدارس الثانوية في محافظات غنزة وسبل تطويره (رسالة ماجستير غير

منشورة). جامعة الأزهر - غزة: فلسطين.

ثانياً: المراجع الأجنبية:

1. Awang, M; Ismail, R; Flett, P. \& Curry, A. (2011). Knowledge Management in Malaysian School Education, Do the Smart Schools do it better?. Quality Awareness in Education: An International Perspective. Emerald Group Publishing Limited, 19(3): 263 - 282, https://doi.org/10.1108/09684881111158063.

2. Balochi, F. (2013). The role of knowledge economy in developing the educational system from the viewpoint of educational supervisors (unpublished master's thesis). Mu'ta University, Jordan.

3. Cheng, E. (2015). Knowledge Management for School Education (a book reading series), Education Observatory Journal (12), Planning and Information Agency, Ministry of Education, Riyadh, Kingdom of Saudi Arabia.

4. Choy, Chong Siong, \& Yong Suk, Choi (2005). Critical Factors in the Successful Implementation of Knowledge Management. Journal of Knowledge Management Practice, Multimedia University, Malaysia; California State University.

5. Kaya, Ayca Bagmen (2019). Knowledge Management for Education Administrators. Bolu Abant Izzet Baysal University. Publication in ResearchGate, at: https://www.researchgate.net/publication/338761644

6. Lung Lee, Chi; Peng Lu, Hsi; Yang, Chyan \& Tse Hou, Huei (2010). A Process-Based Knowledge Management System for Schools: A Case Study in Taiwan, TOJET: The Turkish Online Journal of Educational Technology 9(4):10-21.

7. Mavodza, J. \& Ngulube, P. (2012). Knowledge management practices at an institution of higher learning. SA Journal of Information Management, 14(1), https://doi.org/10.4102/sajim.v14i1.496.

8. McNeil, Rebecca (2011). Application of Knowledge Management for Sustainable Development in Institutions of Higher Education. Dalhousie Journal of Interdisciplinary Management, 7(1), https://doi.org/10.5931/djim.v7i1.82.

9. Mohammad, Mastan \& Jose, G. Jai Arul (2016). An Analysis of Knowledge Management in Educational Institution. International Journal of Applied Sciences and Management. 2(1): 211-218.

10. Nunes, Jose M. Baptista; Saima, Kanwal \& Muhammad, Arif (2017). Knowledge Management Practices in Higher Education Institutions: A Systematic Literature Review. Paper presented at: IFLA WLIC 2017 - Wrocław, Poland - Libraries Solidarity Society.

11. Oxford dictionary. (1993). clarendon press. USA.

12. Roth, Gene L. \& Lee, Young Hae (2009). AConceptual Framework for Examining Knowledge Management in Higher Education Contexts. New Horizons in Adult Education \& Human Resource Development, 23(4): 22-37, https://doi.org/10.1002/nha3.10357.

13. Shalmani, Mohammad Hassan Hassani \& Toorani, Heidar (2016). The application of Bhatt's knowledge management strategy in the organization of schools with the use of selforganized teams of teachers. Problems and Perspectives in Management 14(3): 65-75, https://doi.org/10.21511/ppm.14(3).2016.06.

14. Tadros.I. H., Abdull Rahman. E.J., Read A. A., Kreimeen, R.A. \& Alzoubi, K.N. (2013). The Relation between the Requirements of Knowledge Management and the Academic Human Resources Development in the Colleges of Education in the Jordanian Public Universities. Journal of Engineering Research and Applications, 3(5): 1887-1893. 
المجلة الدولية للدراسـات التربوية والنفسية

International Journal of Educational \& Psychological Studies (EPS)

Journal Homepage: https://www.refaad.com/views/EPSR/Home.aspx

www.refaad.com

ISSN: 2520-4149 (Online) 2520-4130 (Print)

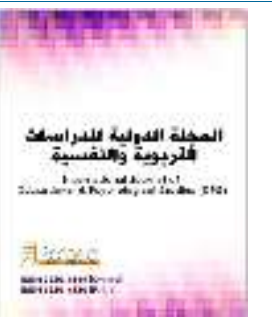

\title{
The degree of availability and importance of requirements for applying knowledge management in educational supervision from the viewpoint of supervisors in the sultanate of Oman
}

\author{
Nesreen Saleh Mohamed Salah El-Din \\ Assistant Professor of Educational Administration, College of Education, Sultan Qaboos University, Sultanate of Oman \\ nesren@squ.edu.om
}

Badria Ali Mohammed Al-Farsi

Educational Supervisor at the General Directorate of Education - Muscat - Sultanate of Oman

b.farsi@moe.om

Received : 14/10/2020 Revised : 27/10/2020 Accepted : 5/11/2020 DOI : https://doi.org/10.31559/EPS2021.9.3.9

Abstract: The research aimed to determine the degree of availability of knowledge management requirements and its importance in educational supervision from the point of view of supervisors in the Sultanate of Oman in light of some variables.

The research used the descriptive method, and the research sample consisted of (181) supervisors, to whom a questionnaire, consisting of (52) Paragraphs, was applied., divided into four main axes. The results showed that the degree of availability of requirements for applying knowledge management in educational supervision in the Sultanate of Oman was low. With a mean (1.64) and a percentage (54.6\%), where the human requirements came first, with a mean (1.82) and a percentage (60.6\%), while the administrative requirements came in the last, with a mean (1.56) and a percentage. (52\%), the degree of importance of applying knowledge management was high from the point of view of supervisors in the Sultanate of Oman, with a mean of (2.64), and a percentage (88\%). The human requirements were the most important, with a mean (2.69) and a percentage (89.6\%), while the legislative and regulatory requirements came in the last in terms of importance, with a mean (2.57) and a percentage (85.6\%). The results did not show any statistically significant differences in the estimates of the total sample members to the degree of availability or importance of the application of knowledge management requirements due to the variable of gender, workplace, or job.

Keywords: knowledge management; knowledge management requirements; educational supervision.

\section{References:}

1. 'bd Alhady, Jwdh 'zt (2002). Aleshraf Altrbwy: Mfahymh Wasalybh. 'man. Aldar Al'lmyh Aldwlyh Llnshr Waltwzy'.

2. 'bd Alwhab, Smyr Mhmd (2006). Mttlbat Ttbyq Edart Alm'rfh Fy Almdn Al'rbyh: Drast Halh 'la Mdynh Alqahrh. Alndwh Aldwlyh Lmdn Alm'rfh. Alm'hd Al'rby Lenma' Almdn. Almdynh Almnwrh.

3. Al'lwyh, Mna (2014). Tswr Mqtrh Ltf'eyl Aleshraf Altrbwy Bmdars Alt'lym Ma B'd Alasasy Bmhafzt Msqt Fy Dw' Nmwdj Aleshraf Almtnw'. (Rsalt Majstyr Ghyr Mnshwrh). Jam't Nzwa. Sltnt 'Eman.

4. 'ly, Asamh Mhmd Syd (2013). Edart Alm'rfh, Atjahat Edaryh M'asrh J (1). Dar Al'lm Alayman Llnshr Waltwzy'. Alqahrh. Jmhwryt Msr Al'rbyh.

5. Al'ly, 'bd Alstar ؛Wqndyljy, 'amr ؛Wal'mry, Ghsan (2006). Almdkhl Ela Edart Alm'rfh. Dar Almsyrh Llnshr Waltwzy', 'man, Alardn. 
6. Ahmd, Mty'h' :Ely, Nayfh ؛Mghrqwnh, Aryj (2017). Waq' Ttbyq 'Emlyat Edart Alm'rfh Fy Almdars Althanwyh W'laqtha Bada' Mdrsyha Mn Wjht Nzrhm Drash Mydanyh Fy Mdynh Alladqyh. Mjlt Jam't Tshryn Llbhwth Waldrasat Al'lmyh: Slslt Aladab Wal'lwm Alensanyh. 39(6): 351- 373.

7. Bdwy, Ahmd Zky (1977). M'jm Mstlhat Al'lwm Alajtma'yh. Byrwt: Mktbt Lbnan.

8. Albtanyh, Mhmd Trky :Almshaqbh, Zyad Mhmd (2010). Adarh Alm'rfh Byn Alnzryh Walttbyq. Dar Jlys Alzman Llnshr Waltwzy'. 'man. Alardn.

9. Alblwshy, Hsyn Bn 'ly (2011). Waq' Edarh Alm'erfh Fy Dwa'r Tnmyt Almward Albshryh Wmkatb Aleshraf Altrbwy Bwzart Altrbyh Walt'lym Fy Sltnt 'man (Rsalt Majstyr Ghyr Mnshwrh). Jam't Alsltan Qabws. Sltnt 'man.

10. Alblwshyh, Fatmh Mwsa (2013). Dwr Alaqtsad Alm'rfy Fy Ttwyr Alnzam Altrbwy Mn Wjht Nzr Almshrfyn Altrbwyyn (Rsalt Majstyr Ghyr Mnshwrh). Jam't M'th. Alardn.

11. Dhawy, Bywmy Mhmd :Almlyjy, Rda Ebrahym (2010). Twjhat Aledarh Altrbwyh Alf'ealh Fy Mjtm' Alm'rfh. Dar Alfkr Al'rby, Alqahrh.

12. Hamd, Mhmd R'wf (2006). Edart Alm'rfh Walabda' Almjtm'y(T3). Alhy'h Almsryh Al'amh Llktab: Mktbt Alasrh. Alqahrh.

13. Alhbsyh, Rya Hmd (2012). Dwr Edart Alm'rfh Fy Tnmyt Almharat Aladaryh Lda Al'amlyn Balmdyryat Al'amh Lltrbyh Walt'lym Bsltnt 'man. (Rsalt Majstyr Ghyr Mnshwrh), Jam't Nzwa. 'man.

14. Alhbsyh, Salmh Ahmd (2017). Drjt Twzyf Alqadh Altrbwyyn Ledarh Alm'rfh Fy Almdars Alhkwmyh Bsltnt 'man Mn Wjht Nzrhm. (Rsalt Majstyr Ghyr Mnshwrh). Aljam'h Al'rbyh Almftwhh. Sltnt 'man.

15. Alhbwb, Asma' Khlf (2010). Dwr Adarh Alm'rfh Fy Ttwyr Ada' Mrakz Aleshraf Altrbwy Fy Mdynt Alryad Mn Wjht Nzr Almshrfat Altrbwyat (Rsalt Majstyr Ghyr Mnshwrh). Jam't M'th. Alardn.

16. Alhrby, 'bd Allh 'wad (2012). Dwr Almshrf Altrbwy Fy Thqyq Mttlbat Mjtm' Alm'rfh Fy Mhafzt Hfr Albatn. Alm'tmr Al'lmy Althany Wal'shrwn Lljm'yt Almsryh Llmnahj Wtrq Altdrys B'nwan: Mnahj Alt'lym Fy Mjtm' 'sr Alm'rfh, 88- 114.

17. Alhrby, Fhd Jhz (2015). Ada' Almshrf Altrbwy Fy Dw' Ttbyq Mttlbat Almjtm' Alm'rfy Bedarat Altrbyh Walt'lym Balmmlkh Al'rbyh Als'wdyh. Mjlt Klyt Altrbyh (102), 26.

18. Aljhwry, Rashd Bn Hmd (2016). Tnmyt Almward Albshryh Bwzart Altrbyh Walt'lym Fy Sltnt 'man Fy Dw' Mdkhl Adart Alm'rfh. (Rsalt Majstyr Ghyr Mnshwrh). Jam't Alsltan Qabws. 'man.

19. Alkbysy, Slah Aldyn (2005). Edarh Alm'rfh. Almnzmh Al'rbyh Lltnmyh Aledaryh. Alqahrh.

20. Alkhrabshh, 'mr Mhmd 'bd Allh (2016). Drjt Ttbyq Edart Alm'rfh Fy Jam't Alblqa' Alttbyqyh Fy Alardn Mn Wjht Nzr A'da' Hy'tha Altdrysyh. Mjlt Drasat Al'lwm Altrbwyh Baljam'h Alardnyh. 43 (5):1829- 1853.

21. Alkhtyb, Ahmd :M'ay'h, 'adl Salm (2009). Aledarh Alhdythh: Nzryat Wastratyjyat Wnmadj Hdythh. 'alm Alktb Alhdyth. 'man. Alardn.

22. Krwan, Mhmd Jmyl (2017). Athr Mttlbat Edart Alm'rfh 'la Alada' Alm'ssy Llbnwk Altjaryh Alardnyh. (Rsalt Majstyr Ghyr Mnshwrh). Jam't 'man Al'rbyh. Alardn.

23. Alksbany, Mhmd (2012). Albhth Altrbwy Byn Alnzryh Walttbyq. Dar Alfkr Al'rby: Alqahrh.

24. Mlkawy, Abrahym Alkhlwf (2007). Adarh Alm'rfh: Almmarsat Walmfahym. Alwraq Llnshr Altwzy'. 'man. Alardn.

25. Almnswry (2011). Drjt Ttbyq 'mlyat Adarh Alm'rfh Fy Jam't Alsltan Qabws Fy Sltnh 'man Mn Wjht Nzr A'da' Hy't Altdrys Fy Alklyat Al'lmyh Walansanyh Altab'h Lha. Jam't Alyrmwk. Alardn.

26. Mwsa, Bsmh Mhmwd (2012). Drjh Ttbyq Edarh Alm'rfh Mn Qbl Mdyry Mdars Almrhltyn Alabtda'yh Walthanwyh Alhkwmyh Fy Alkwyt Mn Wjht Nzr Almdyryn Walmwjhyn Alfnyyn (Rsalh Majstyr Ghyr Mnshwrh). Qsm Aledarh Walqyadh Altrbwyh. Jam't Alshrq Alawst. Alkwyt.

27. Nbyl, Sarh (2016). Mttlbat Ttbyq Edart Alm'rfh. Almntda Al'rby Ledarh Almward Albshryh. Almwq' https://hrdiscussion.com/members/285857.html.

28. Nwr Aldyn, 'sam (2010). Edart Alm'rfh Waltknwlwjya Alhdythh. Dar Asamh Llnshr Waltwzy'. 'man. Alardn.

29. Alqasmyh, 'aydh Bnt Bty (2009). Tswr Mqtrh Llttwyr Aledary Bwzart Altrbyh Walt'lym Bsltnh 'man Fy Dw' Edart Alm'rfh. Jam't Alqahrh. Jmhwryh Msr Al'rbyh.

30. Alqdah, Mhmd Ebrahym (2017). Alhajat Almhnyh Lda Almshrfyn Altrbwyyn Fy Alardn Ela Alkfayat Allazmh Ledart Alm'rfh Fy Dw' Mbad' Synj Llmnzmat Almt'lmh. Mjlh Klyh Altrbyh Fy Al'lwm Altrbwyh: 41(3): 70- 111.

31. Alqtarnh, Zyad Hmd (2011). Edarh Alm'rfh. Dar Jlys Alzman Llnshr Waltwzy'. Alardn.

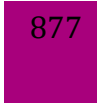

المجلة الدولية للدراسات التربوية والنفسية- المجلد9، العدد3- 2021، ص: 858-878 
32. Al Rhmh, Hyfa' Mhsn (2017). Mttlbat Ttwyr Aleshraf Altrbwy Fy Dw' Altkhtyt Alastratyjy Bsltnt 'man (Rsalt Majstyr Ghyr Mnshwrh). Jam't Alsltan Qabws. Sltnt 'man.

33. Alsha'r, 'dly Dawd (2012). Adart Alm'rfh Mdkhl Lttwyr Aleshraf Altrbwy. Mjlt Albhth Al'lmy Fy Altrbyh. 13(3): 1657- 1684.

34. Shahyn, 'bd Alrhmn Bn Ywsf (2015). Drjt Amtlak Wmmarsh Kfayat Aleshraf Altrbwy Fy Dw' Khsa's Mjtm' Alm'rfh Bmntqt Almdynh Almnwrh. Almnahj Waleshraf Altrbwy. Qsm Altrbyh. Aljam'h Aleslamyh: Als'wdyh.

35. Alshmrany, Hamd Mhmd (2017). Drjt Mmarst M'lmy Wm'lmat Almdars Althanwyh Fy Mhafzt Aldwadmy L'mlyat Edart Alm'rfh Drash Mydanyh. Mjlt Klyt Altrbyh Alasasyh Ll'lwm Altrbwyh Walensanyh Bjam't Babl: (32): 40-52.

36. Tshngh, Eyrl (2015). Edart Alm'rfh Mn Ajl Alt'lym Almdrsy (Slslt Qra'h Fy Ktab). Mjlt Mrsd Alt'lym (12): Wkalt Altkhtyt Walm'lwmat Wzarh Alt'lym, Alryad, Almmlkh Al'rbyh Als'wdyh.

37. Altkryty, S'd Ghalb Yasyn (2004). Nzm Msandh Alqrarat. 'man, Dar Almnahj Llnshr Waltwzy'.

38. Altwysy, Zyad Ahmd (2017). Ald'm Alfny Almqdm Mn Almshrfyn Altrbwyyn Llm'lmyn Fy Dw' M'ayyr Aqtsad Alm'rfh Mn Wjht Nzr Mdyry Almdars Fy Alardn. Mjlt Drasat Al'lwm Altrbwyh: 44(Mlhq): 121 - 132.

39. Tyty, Khdr Msbah Esma'yl (2010). Edart Alm'rfh: Althdyat Waltqnyat Walhlwl. Dar Alhamd Llnshr Waltwzy'. Alardn.

40. Wzart Altrbyh Walt'lym (2005). Dlyl Aleshraf Altrbwy. Msqt. Sltnh 'man.

41. Wzart Altrbyh Walt'lym (2017). Mstjdat Al'ml Aleshrafy. Wrqt 'ml Fy Mltqa Alajadh Fy Aleshraf Altrbwy Bt'lymyh Msqt. Da'rt Aleshraf Altrbwy.

42. Wzart Altrbyh Walt'lym (2019). Alktab Alsnwy Llehsa'at Alt'lymyh 2018- 2019: Alesdar Al 49, Alm'lf, Msqt, Sltnt 'man.

43. Abw Alwfa, Aymn 'ly (2012). Waq' Edart Alm'rfh Fy Aleshraf Altrbwy Balmdars Althanwyh Fy Mhafzat Ghzh Wsbl Ttwyrh (Rsalt Majstyr Ghyr Mnshwrh). Jam't Alazhr- Ghzh: Flstyn.

44. Alzaml, Rym(2003). Edart Alm'rfh Fy Mjtm' Qadr 'la Almnafsh. Mjlt Al'alm Alrqmy (16) [Mjlt Elktrwnyh], Astrj' Btarykh 30 Mayw 2020 Mn Mwq' Www.Aljazirah.Com.

45. Abw Zyd, Ahmd (2005). Alm'rfh Wsna'h Almstqbl. Mjlt Al'rby (61). Alkwyt. 